Discussion Paper No. 02-12

Family Background, Cohort and Education A French-German Comparison

Charlotte Lauer

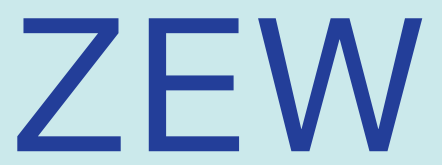

Zentrum für Europäische Wirtschaftsforschung GmbH

Centre for European

Economic Research 
Discussion Paper No. 02-12

\title{
Family Background, Cohort and Education A French-German Comparison
}

\author{
Charlotte Lauer
}

Download this ZEW Discussion Paper from our ftp server:

ftp://ftp.zew.de/pub/zew-docs/dp/dp0212.pdf

Die Discussion Papers dienen einer möglichst schnellen Verbreitung von neueren Forschungsarbeiten des ZEW. Die Beiträge liegen in alleiniger Verantwortung der Autoren und stellen nicht notwendigerweise die Meinung des ZEW dar.

Discussion Papers are intended to make results of ZEW research promptly available to other economists in order to encourage discussion and suggestions for revisions. The authors are solely responsible for the contents which do not necessarily represent the opinion of the ZEW. 


\title{
Family Background, Cohort and Education A French-German Comparison
}

\author{
Charlotte Lauer \\ Centre for European Economic Research \\ Zentrum für Europäische Wirtschaftsforschung (ZEW) \\ Mannheim \\ Equipe de Recherche sur les Marchés, l'Emploi et la Simulation \\ ERMES-CNRS, University of Panthéon-Assas \\ Paris
}

\begin{abstract}
This paper analyses the impact of family background, gender and cohort on educational attainment in France and Germany, relying on a theoretical model imbedded in the human capital theory. In a second step, the educational process is decomposed into school and post-school achievement. The same conceptual framework applies at both stages, but a correlation is permitted between them. Empirically, this boils down to estimating a multivariate ordered probit model. The results show that in spite of huge differences in the distribution of education in France and Germany, these countries prove surprisingly similar with respect to the impact of family background and cohorts. However, there are significant dissimilarities depending on the stage observed in the educational career, in particular with respect to gender differences.
\end{abstract}

JEL classification: I2; C5

Keywords: Educational attainment; Multivariate ordered probit

\section{Acknowledgement:}

Financial support from the Fritz Thyssen Foundation under the project

"Qualifikation und Arbeitsmarkterfolg in Deutschland und Frankreich" is gratefully acknowledged. 


\section{Introduction}

In France and Germany like in most industrialised countries, the level of educational attainment has risen steadily over the past century. This educational expansion has been largely encouraged by public authorities, which devote a non-negligible part of their financial resources to education (5.1 percent of national GDPs on average in OECD countries in 1997, OECD (2000)). Beyond the level of compulsory schooling, however, public authorities can only influence educational participation by setting incentives. This, in turn, can only be efficient if the factors which influence the educational decisions of individuals are known, both in order to identify where the needs are and possibly to gain evidence on the effectiveness of the means employed. Beside the usefulness of getting knowledge on the structure and determinants of educational attainment with the aim of influencing educational outcomes, it is also essential for policy-makers to gain evidence on what determines educational outcomes if they are to plan educational needs for the future.

France and Germany are quite different in terms of the distribution of educational attainment in the population. These differences certainly reflect the different organisation of the education system as well as different preferences in society, but it may also be explainable for a part by a different influence of certain factors on individual educational achievement. Therefore, it should be of interest to examine and compare the impact of certain factors on educational outcomes in both countries. This is the aim of this study. In the 1970s, in the context of a strong educational expansion, there has been quite a large number of sociological studies related to educational decisions and educational inequality, in Germany (see for instance the detailed review of Kristen (1999)) like in France (e.g. Bourdieu and Passeron (1970) and Boudon (1973)). More recently, Blossfeld (1993) but also Müller and Haun (1994) and Dustmann (2001) examined the issue of educational inequality across social groups and its changes over time in Germany, while Goux and Maurin (1997) and Thélot and Vallet (2000) examined, among others, this issue for France. Overall, however, the literature available for France and Germany primarily aims at exploring the statistical link between social origin and educational achievement without being imbedded in a theoretical model. Moreover, there is an undoubtable lack of comparative studies on this topic for France and Germany, and the literature available generally has a national focus. The following analyses are an attempt to fill this gap in empirical research.

The paper is structured as follows. After presenting in section 2 the essential features of the French and the German education systems in a comparative perspective, section 3 proposes a comparative analysis of the determinants of final educational attainment in France and Germany, whereby the modelling framework explained in section 3.1 is directly applied to French and German data in section 3.2. Then, in section 4, a closer look is taken at the process of educational attainment. To this end, the model is extended so as to decompose the educational career into successive stages. Thus, in section 4.1, the final educational outcome is modelled as the result 
of two decisions: the decision on school education and that on post-school education, whereby a correlation between these decisions is permitted. This theoretical model is then applied in order to gain empirical on France and Germany (section 4.2). Finally, section 5 concludes.

\section{The education system in France and Germany}

The organisation of the education system is quite different in France and Germany (see a detailed comparison in Lauer (2001)). In Germany, education policy is primarily the responsibility of the Länder, the German federal states, whereas in France, the basic competence falls to the central State.

In France, education - but not school attendance - is compulsory from age 6 to age 16, i.e. for 10 years, but in practice, almost all children aged between 3 and 6 go to the nursery schools, which are an integral part of the education system. In Germany, the Kindergärten, the traditional form of pre-school education, do not fall under an educational jurisdiction and are only attended by part of the children. There, school attendance - not only education - is compulsory for all children over 6 years of age for 9 years of full-time general education plus 3 years of either general education or part-time education in vocational training schools. Primary education spans over 4 years in Germany, generally on a half-day basis, while it lasts 5 years in France, on a full-day basis. An essential difference between France and Germany is that after the common primary education, German pupils are streamed into different types of schools according to their abilities (typically the Hauptschule, the Realschule and the Gymnasium, the latter entitling to university studies), whereas as a rule, all French children follow a common core curriculum at the same schools (collèges) throughout lower secondary education. A differentiation of educational track appears only at the upper secondary level in France.

Another essential difference between France and Germany concerns their respective conceptions of education. In France, general education is more prized than vocational education and the general maturity certificate (Baccalauréat) has a key position. Only if pupils fail on the way to Baccalauréat completion will they opt for a deviant track, vocational education. In other words, vocational education is reserved to the "selected-out" of the general education system and qualifications like the CAP (Certificat d'Aptitude Professionnelle) or BEP (Brevet d'Etudes Professionnelles), which more or less correspond to the German apprenticeship, have a very low status. In Germany, no comparable primacy of general education over vocational education is observable. Vocational education, via the apprenticeship system ("dual system") inherited from the Middle-Age, is an essential component of the education system, and that is the track most young persons choose.

At the tertiary level, there are also noticeable differences. The German system is relatively homogeneous, with the central position of universities and the existence 
of the more practically oriented Fachhochschulen. The French landscape of higher education is more strongly differentiated. Indeed, at a given education level, different types of private and public institutions (universities, Grandes Ecoles, institutes etc.) coexist and offer a wide range of study programmes with different purposes and approaches. Moreover, the vertical stratification is also much more pronounced in France than in Germany. There exists, on the one hand, a large number of shorttrack and practically oriented tertiary level studies (BTS, DUT etc.) and, on the other hand, elite institutions, the so-called Grandes Ecoles, which both have no equivalent in Germany.

Concerning the distribution of educational degrees in the population, one can observe that there is a stronger dispersion in France than in Germany. This is the case at the secondary level, where more French people have no school degree at all (about 30 percent in France against 5 percent in Germany in 1999, Lauer (2001)), while on the other hand more French people hold the general maturity certificate (24 percent in France against 16 percent in Germany in 1999, Lauer (2001)). This is also true in terms of final educational attainment. The distribution of final education in Germany is concentrated around basic and advanced vocational qualifications (around 60 percent of the population in 1999), whereas a larger proportion of the French population disposes either of no degree at all, while at the upper end of the distribution, also more French than German people possess a higher education degree. Moreover, at the same level of vocational education, French people hold on average a higher level of general education. For a detailed comparison of the education system and of the qualification structure in France and Germany, please see Lauer (2001).

These differences in the distribution of educational outcomes certainly reflect the different organisation of the education system as well as different preferences in society, but it may also be explainable for a part by a different influence of certain factors on individual educational achievement. Therefore, it should be of interest to examine and compare the impact of certain factors on educational outcomes in both countries. This implies that we find an appropriate way to model and estimate this empirically. This paper is an application of the model developed in Lauer (2002). In a first step, section 3 analyses the impact of some essential factors on final educational attainment in France and Germany, and in a second step, section 4 go into more detail in the educational process and decomposes the ultimate educational outcome into school and post-school educational attainment, taking problems of dynamic selectivity into account. 


\section{Determinants of final educational attainment}

First of all, the modelling framework for the analysis of final educational attainment is briefly explained in section 3.1 (for further details, please refer to Lauer (2002)). The application of the model to the case of France and Germany is presented in section 3.2 .

\subsection{Modelling framework}

The principle of the model is that each individual chooses, given some constraints, how much he wants to invest in education, i.e. chooses the education $E$ he wants to acquire among $J$ educational alternatives $E_{j}$ of increasing levels, with $j \in\{1 \ldots J\}$. $E^{*}$ is the desired educational level. The desired level of education is not observable, but only the actual decision $E_{j}$ of the individual, i.e. the education level j actually chosen. The decision is assumed to be rational in the sense that it maximises the perceived utility for the individual, subject to some constraints. The perceived utility is defined as the expected net returns, i.e. the difference between expected returns and expected costs of each educational alternative $E_{j}$, given some characteristics. The concept of utility may cover monetary as well as non monetary aspects. Thus, the optimal educational decision for an individual with a given vector of characteristics $x$ is given by:

$$
\operatorname{Max}_{j \in\{1 \ldots J\}} r\left(E_{j} \mid x\right)-c\left(E_{j} \mid x\right)
$$

where $r$ denotes the expected return and $c$ the expected cost associated with educational level $E_{j}$. The costs and returns of education may differ across individuals and it is assumed that they are affected by characteristics observable to the scientist and by some other unobserved factors in the following way:

$$
\begin{aligned}
r\left(E_{j} \mid x\right) & =r\left(E_{j}\right) \varphi_{r}(x) \varepsilon_{r} \\
c\left(E_{j} \mid x\right) & =c\left(E_{j}\right) \varphi_{c}(x) \varepsilon_{c}
\end{aligned}
$$

where the function $\varphi_{r}(x)$ (resp. $\varphi_{c}(x)$ ) defines the effects of the observed characteristics on the expected returns (resp. costs) of education and the random variable $\varepsilon_{r}$ (resp. $\varepsilon_{c}$ ) accounts for the effect of unobserved individual heterogeneity on the expected returns (resp. costs). It is assumed that $E\left(\varepsilon_{r}\right)=E\left(\varepsilon_{c}\right)=1$, meaning that unobserved heterogeneity has on average a neutral effect on the return as well as on the cost expectations.

The optimal educational decision $E_{j^{*}}$ is such that the expected net return is maximised, i.e. the net return associated with $E_{j^{*}}$ must be positive, larger than the net returns expected from the next lower education level $E_{j^{*}-1}$ and at least as large as those expected from the next higher education level $E_{j^{*}+1}{ }^{1}$. Writing these assumptions down, it can be shown (see Lauer (2002)) that:

1 If the net return is equal for $E_{j}$ and $E_{j+1}$, the individual is assumed to choose alternative $E_{j}$. 


$$
\operatorname{Pr}\left(E_{j} \mid x\right)=\operatorname{Pr}\left[\frac{c\left(E_{j}\right)-c\left(E_{j-1}\right)}{r\left(E_{j}\right)-r\left(E_{j-1}\right)} \cdot \frac{1}{\varphi(x)}<\varepsilon \leq \frac{c\left(E_{j+1}\right)-c\left(E_{j}\right)}{r\left(E_{j+1}\right)-r\left(E_{j}\right)} \cdot \frac{1}{\varphi(x)}\right]
$$

where $\varphi(x)=\frac{\varphi_{r}(x)}{\varphi_{c}(x)}$ and $\varepsilon=\frac{\varepsilon_{r}}{\varepsilon_{c}}$.

$\varphi(x)$ measures the net impact of observed characteristics $x$ and $\varepsilon$ the net effect of unobserved individual heterogeneity on the expected relation of returns to costs. Thus, any change in the observed characteristics $x$ may change educational decisions to the extent that it affects the expected ratios of marginal costs to marginal returns from the next lower level and to the next higher level. Note that in this model, it is not necessary to assess the actual costs and returns of each educational alternative, but it is enough to determine how the observed characteristics influence the perceived ratio of costs to returns. To simplify the notation, let us call:

$$
\mu_{j}=\ln \left(\frac{c\left(E_{j+1}\right)-c\left(E_{j}\right)}{r\left(E_{j+1}\right)-r\left(E_{j}\right)}\right)
$$

Taking the logarithm of the expression in brackets in equation (3) and assuming that $\varphi(x)=\exp [\beta x]$, we obtain:

$$
\operatorname{Pr}\left(E_{j} \mid x\right)=\operatorname{Pr}\left[\mu_{j-1}-\beta x<\ln \varepsilon \leq \mu_{j}-\beta x\right]
$$

If we assume that $\ln \varepsilon$ is normally distributed with mean 0 and variance $1^{2}$, equation (5) may be rewritten as

$$
\operatorname{Pr}\left(E_{j} \mid x\right)=\Phi\left(\mu_{j}-\beta x\right)-\Phi\left(\mu_{j-1}-\beta x\right)
$$

where and $\Phi$ is the cumulative standard normal distribution function. This expression takes the familiar form of an ordered probit model, where the $\mu_{j}$ 's are the cut values. The parameters $\beta$ and the cut values $\mu_{j}$ can easily be estimated empirically by maximising the following log-likelihood function, where $I_{i j}$ is an indicator variable equal to 1 if the individual $i, i \in\{1 \ldots n\}$ opts for educational level $E_{j}$ and 0 otherwise:

$$
\ln \mathcal{L}=\sum_{i=1}^{n} \sum_{j=1}^{J} I_{i j} \ln \left[\Phi\left(\mu_{j}-\beta x_{i}\right)-\Phi\left(\mu_{j-1}-\beta x_{i}\right)\right]
$$

2 Such an ordered probit model can only be identified up to some factor of proportionality. Since this is the ratio of the parameters to the theoretical $\sigma$ which matters, it is convenient to normalise $\sigma$ to 1 (Maddala, 1983, p.23). 


\subsection{Estimation for France and Germany}

In this section, the model is directly applied to the case of France and Germany.

\subsubsection{Definition of the variables}

The estimations are based on the GSOEP data for Germany and on the FQP data for France (see the description of the data sets in appendix), which entail, among others, comparable information on education and family background. Only those individuals residing in West Germany have been retained for the analysis and for both countries, the sample selected here consists of the cohorts born between 1929 and $1968^{3}$. This leaves us with an estimation sample of about 6,000 individuals for Germany, and around 15,000 individuals for France. The priority has been given to achieving the highest degree of comparability as possible. The price to pay for it is that we have to give up the information which is only available for one country.

We cannot model the educational decision as such, since we have no information on what motivates individuals in their educational choices, but we can postulate that the educational outcome we observe is the result of the decision made by the individual. The dependent variable is defined as the highest degree obtained. The correspondence scale used for educational attainment measured by the highest degree obtained in France and Germany is the following (table 1):

Table 1: Definition of dependent variable: final educational attainment

\begin{tabular}{lll}
\hline \hline Education level & \multicolumn{1}{c}{ Germany } & \multicolumn{1}{c}{ France } \\
\hline$E_{1}$ No vocational degree & No voc. degree & No voc. degree \\
$E_{2}$ Basic vocational degree & Lehre & CAP/BEP \\
$E_{3}$ Intermediate qualification & Fachschule/Abitur & Baccalauréat level \\
$E_{4}$ Lower tertiary & Fachhochschule & Baccalauréat+2 level \\
$E_{5}$ Upper tertiary & Universität & Above Baccalauréat+2 level \\
\hline \hline
\end{tabular}

The lowest education level $E_{1}$ is assigned to the individuals who do not hold any vocational qualification and at most a school degree which do not entitle them to pursue tertiary level studies. Education level $E_{2}$ (basic vocational degree) typically corresponds to an apprenticeship (Lehre) in Germany or a CAP/BEP degree in France, or any comparable vocational degree which do not qualify for higher education. Education level $E_{3}$ (intermediate qualification) is assigned to individuals who hold either an advanced vocational qualification (like a degree from a technical college or a master craftsman degree) and/or are in possession of the general or

3 In order to avoid problems of too large age differences between the cohorts while keeping the number of observations as large as possible, for Germany, the cohorts born before 1948 are taken from the 1985 wave of the panel, while cohorts born after 1948 are drawn from the 1999 wave. All the cohorts are taken from the 1993 FQP wave for France, since this is the only wave available. 
vocational maturity certificate (Abitur/Fachhochschulreife or Baccalauréat level). $E_{4}$ correponds to the the lower tertiary level (Fachhochschule in Germany or Baccalauréat+2 in France, and $E_{5}$ to the upper tertiary level.

To keep in line with usual pratice in empirical literature and given the information available in both data sets, the independent variables consist of birth cohort dummies (born between 1929 and 1938 as the reference category, born between 1939 and 1948, born between 1949 and 1958 and born between 1959 and 1968) in order to examine changes across generations and of a series of variables depicting family background. Parental background might affect offspring's educational outcomes through the availability of financial resources within the family. In the presence of imperfect capital markets, and in case the parents do not dispose of enough money, then, investment in education might be limited by credit constraints (Rosenzweig and Wolpin (1993)). Neither the GSOEP nor the FQP Survey contain information on parental income. However, there is in both data sets information on the occupational situation of the father during the childhood of the individual ${ }^{4}$. This can serve as an indicator of the probable financial situation of the household the individual grew up in, which affects cost to return expectations, especially through the cost side. The variable on occupational position is more detailed for France than for Germany, but it proved possible to aggregate the available information so as to build a comparable set of dummy variables for both countries. Thus, the occupational position of the father is defined as worker (reference category), farmer, self-employed, senior manager, middle manager or employee. A dummy for missing information on the father's occupation is also included in order to avoid problems of selective sample composition due to non-randomly missing information. This is all the more important since the pattern of missing information could be different in France and in Germany. Furthermore, another set of dummies describe the education level of the parents. For France like for Germany, this information is available for both the mother and the father. The same correspondence scale as before has been used for the education of the parents: no vocational degree (reference category), basic vocational degree, intermediate qualification and higher education (lower or upper tertiary taken together). Here again, a dummy for missing information has been added to control for non-randomly information, without being an object of analysis as such.

\subsubsection{Estimation results}

Table 2 presents the results of specification tests. The first series of $\chi^{2}$-tests aims at examining whether the parameters differ significantly between men and women, in which case the specification should account for this. The tests on gender differences are based on an estimation of the model described in section 3, with the five-level dependent variable described above, which includes in addition to the explanatory

4 For France, we also have information on the occupational position of the mother, but since this information is not available for Germany, the variable has not been included in the estimations. 
variables further dummies constructed by interacting all the explanatory variables with a dummy variable for gender ( 1 if the individual is a female, 0 if he is a male).

Table 2: Test results

\begin{tabular}{lrrrr}
\hline \hline & \multicolumn{2}{c}{ Germany } & \multicolumn{2}{c}{ France } \\
Null hypothesis & $\chi^{2}$ & $\mathbf{p}>\chi^{2}$ & $\chi^{2}$ & $\mathbf{p}>\chi^{2}$ \\
\hline Female $^{*}$ Birth cohort $=0$ & 61.59 & 0.00 & 74.54 & 0.00 \\
Female $^{*}$ Mother's education $=0$ & 2.52 & 0.64 & 6.93 & 0.14 \\
Female $^{*}$ Father's education $=0$ & 7.37 & 0.12 & 11.82 & 0.02 \\
Female ${ }^{*}$ Father's occupation $=0$ & 1.82 & 0.94 & 23.80 & 0.00 \\
$\mu_{1}:$ Male $=$ Female & 227.86 & 0.00 & 79.71 & 0.00 \\
$\mu_{2}:$ Male $=$ Female & 182.69 & 0.00 & 19.35 & 0.00 \\
$\mu_{3}:$ Male $=$ Female & 154.67 & 0.00 & 26.58 & 0.00 \\
$\mu_{4}:$ Male $=$ Female & 114.82 & 0.00 & 73.64 & 0.00 \\
Males: $\quad \mu_{1}=\mu_{2}$ & $2,042.40$ & 0.00 & $3,057.68$ & 0.00 \\
$\quad \mu_{2}=\mu_{3}$ & 814.33 & 0.00 & 918.46 & 0.00 \\
$\quad \mu_{3}=\mu_{4}$ & 211.85 & 0.00 & 472.04 & 0.00 \\
Females: $\quad \mu_{1}=\mu_{2}$ & $2,145.92$ & 0.00 & $2,174.06$ & 0.00 \\
$\quad \mu_{2}=\mu_{3}$ & 532.03 & 0.00 & $1,109.48$ & 0.00 \\
$\mu_{3}=\mu_{4}$ & 87.08 & 0.00 & 746.97 & 0.00 \\
\hline \hline
\end{tabular}

For Germany, the null hypothesis that all the interaction dummies for one set of variables are not jointly significantly different from zero is only rejected for the birth cohort variables (at a 1 percent significant level). For the other variables, the null hypothesis cannot be rejected at the 10 percent level, which means that gender differences in the impact of the family background variables are not significant in a statistical sense in Germany. A significance level of at least 10 percent has been retained as a criterion for the interaction dummies to be included in the final specification. Thus, only the interaction terms between the birth cohort and gender have been retained in the final specification for Germany. In France, however, the test results show that there are noticeable gender differences (significant at a 1 percent level) in the cohort effects, like in Germany, but also in the impact of father's education and occupation on the child's educational prospects. Therefore, we include interaction dummies for the cohort variables, but also for the father's background in the final estimation for France.

Furthermore, possible gender differences in the threshold values $\mu_{j}$ have also been tested, since there is no a priori reason to assume that the thresholds should be the same for men and women, even though this is a common assumption in empirical literature as far as ordered probit estimations are concerned. The test results in table 2 are based on a specification which includes only the significant interaction terms as explained above and allow the threshold values to differ between men and 
women ${ }^{5}$. As can be seen, all the threshold values differ significantly between men and women at the 1 percent level, for both countries. Therefore, it seems useful to allow the threshold values to differ across genders in the finally retained specifications. In a next step, $\chi^{2}$-tests on the threshold values were run in order to ensure that the categories of the dependent variable are really distinct. The hypothesis that the thresholds are not distinct has been tested, for both males and females. If two consecutive thresholds proved not to be statistically different, then, the educational categories should be aggregated. The test results show that for both countries, the educational categories have been defined in an appropriate way since all threshold values differ significantly from each other, both for males and females.

Table 3 reports the estimation results. The estimated coefficients should be interpreted in a qualitative way: a positive and significant coefficient means that a value of one for the dummy variable is associated with a higher probability of reaching a higher level of educational attainment compared to the reference category ${ }^{6}$. A Wald test performed on the hypothesis that all coefficients except the threshold values are zero is rejected at the 1 percent level for France like for Germany.

The impact of the birth cohort on educational outcomes presents obvious similarities in France and Germany. To obtain the overall effect of belonging to one cohort instead of belonging to the reference cohort 1929-38, one adds the coefficient of the simple cohort dummy to that of the same cohort dummy interacted with the gender dummy ${ }^{7}$. As can be seen, the cohort coefficients are significant, positive and increasing, which means that, all else equal, the cost to return ratio associated with education has decreased over the generations in both countries. However, the rise in the net utility of education from one generation to the next becomes increasingly small $^{8}$. There are significant differences between men and women in the cohort effects in both countries. The interactions with the female dummy are positive and increasing, which implies that the gap in the cost to return ratio in favour of men

5 This cannot be estimated directly with the ordered probit command of Stata 7.0 but is easily programmable (see Gould and Sribney (1999)).

6 It also means that the variable increases the probability of achieving the highest education category $E_{5}$ and decreases that of achieving only the lowest category $E_{1}$. For the intermediate categories, one can only say that a positive coefficient increases the probability of holding at least $E_{2}$ or of holding at least $E_{3}$. However, in order to obtain a precise measure of the impact of a variable on the probability of achieving exactly one specific education level, one needs to compute equation (6).

7 For Germany: $0.27+0.14=+0.41$ for the $1939-48$ cohort, $0.34+0.45=+0.79$ for the $1949-58$ generation and $0.22+0.60=+0.82$ for the $1959-68$ generation. For France: $0.43-0.05=+0.38$ for the $1939-48$ cohort, $0.47+0.21=0.68$ for the $1949-58$ generation and $0.50+0.36=0.86$ for the $1959-68$ generation. All these effects are relative to the reference cohort 1929-38.

8 For Germany: +0.41 for the 1939-48 cohort compared to the previous cohort 1929-38, 0.79$0.41=+0.38$ for the 1949-58 cohort compared to the previous cohort $1939-48$ and $0.82-0.79=0.03$ for the 1959-68 cohort compared to the previous cohort 1949-58. For France: +0.38 for the 1939-48 cohort compared to the previous cohort 1929-38, 0.68-0.38 $=+30$ for the 1949-58 cohort compared to the previous cohort $1939-48$ and $0.86-0.68=0.18$ for the $1959-68$ cohort compared to the previous cohort 1949-58. 
has decreased over time and that educational expansion has been stronger among women than among men. The decrease in the gap proves to be stronger in Germany, where educational expansion among women seems to have been stronger than in France, all other things equal.

In both countries, parental education has a significant impact on children's educational outcomes. Thus, the higher the education of the parents is, the higher

Table 3: Determinants of final educational attainment

\begin{tabular}{|c|c|c|c|c|}
\hline \multirow[b]{2}{*}{ Variable } & \multicolumn{2}{|c|}{ Germany } & \multicolumn{2}{|c|}{ France } \\
\hline & coef. & $(\mathrm{s.e})$ & coef. & (s.e) \\
\hline \multicolumn{5}{|l|}{ Birth cohort (ref.: 1929-38) } \\
\hline $1939-48$ & $0.27^{* *}$ & $(0.06)$ & $0.43^{* *}$ & $(0.04)$ \\
\hline $1949-58$ & $0.34^{* *}$ & $(0.06)$ & $0.47^{* *}$ & $(0.04)$ \\
\hline $1959-68$ & $0.22^{* *}$ & $(0.06)$ & $0.50^{* *}$ & $(0.04)$ \\
\hline Female * 1939-48 & $0.14^{\dagger}$ & $(0.08)$ & -0.05 & $(0.06)$ \\
\hline Female $* 1949-58$ & $0.45^{* *}$ & $(0.09)$ & $0.21^{* *}$ & $(0.06)$ \\
\hline Female $^{*} 1959-68$ & $0.60^{* *}$ & $(0.08)$ & $0.36^{* *}$ & $(0.06)$ \\
\hline \multicolumn{5}{|c|}{ Mother's education (ref.: No voc. degree) } \\
\hline Basic voc. degree & $0.22^{* *}$ & $(0.03)$ & $0.21^{* *}$ & $(0.04)$ \\
\hline Intermediate qualif. & $0.36^{* *}$ & $(0.09)$ & $0.64^{* *}$ & $(0.05)$ \\
\hline Higher education & $0.96^{* *}$ & $(0.13)$ & $0.53^{* *}$ & $(0.06)$ \\
\hline Missing & 0.05 & $(0.06)$ & -0.02 & $(0.07)$ \\
\hline \multicolumn{5}{|c|}{ Father's education (ref.: No voc. degree) } \\
\hline Basic voc. degree & $0.27^{* *}$ & $(0.05)$ & $0.20^{* *}$ & $(0.04)$ \\
\hline Intermediate qualif. & $0.40^{* *}$ & $(0.06)$ & $0.53^{* *}$ & $(0.06)$ \\
\hline Higher education & $0.87^{* *}$ & $(0.08)$ & $0.96^{* *}$ & $(0.07)$ \\
\hline Missing & $0.13^{\dagger}$ & $(0.07)$ & $-0.35^{* *}$ & $(0.08)$ \\
\hline Female ${ }^{*}$ Basic voc. degree & & & $0.13^{*}$ & $(0.06)$ \\
\hline Female ${ }^{*}$ Interm. qualif. & & & 0.07 & $(0.09)$ \\
\hline Female $*$ Higher education & & & -0.11 & $(0.09)$ \\
\hline Female $*$ Missing & & & 0.11 & $(0.10)$ \\
\hline \multicolumn{5}{|c|}{ Father's occupation (ref.: Worker) } \\
\hline Farmer & $0.18^{* *}$ & $(0.07)$ & $-0.08^{\dagger}$ & $(0.04)$ \\
\hline Self-employed & $0.48^{* *}$ & $(0.06)$ & $0.36^{* *}$ & $(0.05)$ \\
\hline Senior manager & $0.89^{* *}$ & $(0.06)$ & $0.69^{* *}$ & $(0.06)$ \\
\hline Middle manager & $0.56^{* *}$ & $(0.05)$ & $0.46^{* *}$ & $(0.05)$ \\
\hline Employee & $0.34^{* *}$ & $(0.07)$ & $0.37^{* *}$ & $(0.05)$ \\
\hline Missing & $0.14^{* *}$ & $(0.04)$ & $0.38^{* *}$ & $(0.04)$ \\
\hline Female ${ }^{*}$ Farmer & & & $0.23^{* *}$ & $(0.06)$ \\
\hline Female $*$ Self-employed & & & $0.25^{* *}$ & $(0.06)$ \\
\hline Female $*$ Senior manager & & & 0.11 & $(0.09)$ \\
\hline Female ${ }^{*}$ Middle manager & & & $0.16^{*}$ & $(0.07)$ \\
\hline Female $*$ Employee & & & 0.11 & $(0.07)$ \\
\hline Female $*$ Missing & & & 0.08 & $(0.06)$ \\
\hline
\end{tabular}




\begin{tabular}{llrrrr}
\hline \hline & & \multicolumn{2}{c}{ Germany } & \multicolumn{2}{c}{ France } \\
Variable & coef. & (s.e) & coef. & (s.e) \\
\hline Thresholds & & & & & \\
$\mu_{1} \quad$ Male & $-0.55^{* *}$ & $(0.06)$ & $0.51^{* *}$ & $(0.04)$ \\
& Female & $0.44^{* *}$ & $(0.06)$ & $1.00^{* *}$ & $(0.04)$ \\
$\mu_{2} \quad$ Male & $1.07^{* *}$ & $(0.06)$ & $1.47^{* *}$ & $(0.04)$ \\
& Female & $1.98^{* *}$ & $(0.07)$ & $1.73^{* *}$ & $(0.04)$ \\
$\mu_{3} \quad$ Male & $1.82^{* *}$ & $(0.06)$ & $1.97^{* *}$ & $(0.04)$ \\
& Female & $2.74^{* *}$ & $(0.07)$ & $2.28^{* *}$ & $(0.04)$ \\
$\mu_{4} \quad$ Male & $2.13^{* *}$ & $(0.07)$ & $2.35^{* *}$ & $(0.05)$ \\
& Female & $2.97^{* *}$ & $(0.07)$ & $2.92^{* *}$ & $(0.05)$ \\
\hline Observations & 6,005 & & 15,037 & \\
Log-likelihood & & $-7,122.45$ & & $-17,919.69$ & \\
& & $\chi^{2}$ & $\mathrm{p}>\chi^{2}$ & $\chi^{2}$ & $\mathrm{p}>\chi^{2}$ \\
Wald test & & $1,436.25$ & 0.00 & $2,702.40$ & 0.00 \\
\hline \hline Significance level : $\dagger: 10 \%$ & $*: 5 \%$ & $* *: 1 \%$ & & &
\end{tabular}

education of their children will be. This may be because children growing up in families where the education level of the parents is high inherit to some extent the learning ability of their parents, which diminishes the costs of acquiring education and therefore - to stick to the model notation - lowers the thresholds. A high ability might also help to better convert education into utility (e.g. wages, free time use) and thus increases the return, which further lowers the thresholds. Moreover, highly educated parents generally place greater value on education and are therefore more likely to encourage their offsprings to pursue further studies. Thus, the perception of the return to education is expected to be higher among sons and daughters of highly educated persons. In particular, having parents who hold a higher education degree seems to particularly favour educational prospects, especially in Germany, where there is a big jump in the coefficient from parents with intermediate qualification to parents with higher education. In France, this is also the case - though to a lesser extent for mothers - but having parent's with a Baccalauréat degree means already a decisive improvement for children's educational prospects. The impact of father's education has the same order of magnitude as that of mother's education except for a stronger effect of higher education of fathers than of mothers in France - even though the occupational position of the father is controlled for, while we have no information on the mother's occupational position ${ }^{9}$. Having a father with a basic vocational degree compared to one with no degree improves the educational prospects slightly more for women than for men in France. Otherwise, there does not seem to be any other significant gender differences in the impact of parent's education on children's educational outcomes.

9 Therefore, the influence of mother's education may be of indirect nature and partly stem from the correlated, but unobserved effect of the mother's occupational position. 
As far as the occupational position of the father is concerned, France and Germany prove very similar. All coefficients are positive ${ }^{10}$ and significant for both countries, which means that the offsprings of blue collar workers (the reference category) have the worst educational prospects. The order of magnitude of the coefficients is surprisingly similar. The best educational opportunities, all other things equal, have children of senior managers, followed by those of intermediate level managers $(0.46+0.16=0.62$ for France $)$ and self-employed $(0.36+0.25=0.61$ for France $)$. Children of farmers have only a slight advantage in terms of educational attainment compared to worker's children ${ }^{11}$, but are significantly disadvantaged compared to children of employees. These results might be the consequence of financial constraints which raise the costs of investing in education and thus enhance the cost to return ratio. This could also reflect different systems of preferences, e.g. worker families place less value on education than other and children growing up in those families would expect a lower utility from education or higher costs than other families. In Germany, there are no significant differences between men and women, contrary to France, where daughters of farmers and self-employed (and to a lesser extent of middle staff managers) have significantly better prospects compared to their male counterparts.

As seen before, there are significant differences in the threshold values between men and women in both countries ${ }^{12}$. To be more specific, women have systematically higher thresholds than men, at all education levels. This means that for a given family background and a given cohort, women expect higher costs or lower returns to education and invest less in education than their male counterparts. Interestingly, the gap between men and women in the value of the thresholds is higher in Germany than in France, which means that, all else equal, women are more at a disadvantage in Germany than in France in terms of educational outcomes.

To sum up, it seems that the differences between France and Germany in the structure of educational attainment cannot be explained by a difference in the influence of the factors we could identify as determining the educational outcomes. In fact, both countries have faced an educational expansion of the same order of magnitude and more pronounced for women, and the family background variables exert a very similar impact. However, there is an important difference between France and Germany: if in both countries, access to education is more difficult for women, for a given background, women's handicap is greater in Germany, as the comparatively higher thresholds show.

10 The overall impact of being a farmer's child compared to a worker's child is also positive in France $(-0.08+0.23=0.15)$.

11 In France, having a farmer rather than a worker as a father is only an advantage for women, while sons of farmers face slightly more unfavourable educational prospects than wokers' children.

12 Note that one cannot compare the absolute value of the thresholds, just like one cannot compare the constant term of two OLS regressions. 


\section{Decomposition of the educational career}

The model applied above is very simple to implement empirically and provides a convenient interpretation framework for the analysis of the determinants of educational attainment. In particular, it allows an interpretation of the cut values obtained through the ordered probit estimation which makes sense in economic terms. In a further step, it may be of interest to examine at which stage of the educational career which factors exert an influence. As a matter of facts, some factors might influence educational decisions more decisively (or exclusively) at an earlier stage of the educational career, other at a later stage or exert a different influence at either stages. For instance, has the observed educational expansion taken place at all levels? Does parental background play a more important role for earlier or for later stages of the educational process? Are gender differences similar throughout the educational career? Moreover, changes in the environment at a given stage, such as a reform in the educational system or changing economic conditions, changing situation of the parents, new information, or simply personality development over time, might modify the appreciation of returns and costs and therefore induce a reorientation of decisions for subsequent stages.

In order to examine these issues, the ultimate educational outcome is now decomposed into two decisions: the decision upon general secondary education and that upon post-secondary education, given the level attained in general secondary education. In practical terms, an appealing approach owing to its simplicity would be to consider that for each transition, the model explained in section 3 applies, i.e. after having completed secondary education, individuals decide on their post-secondary education, given the new set of variables and the choices available, independently of their previous choices. Practically, this would result in a sequential-response model, which only differs from the textbook models as presented in Amemiya (1986) pp.310, Maddala (1983) pp.49 or Gouriéroux (1989) pp.249 through the fact that we have an ordered choice instead of a binary choice. However, this approach is only valid under the assumption that the probability of the choice at the second decision point is independent of the choice at the first point, i.e. that the random factors influencing responses at various stages are independent. Otherwise, the estimated coefficients will be biased. Since a selection with respect to unobservable factors may take place, as argue Cameron and Heckman (1998), we do not want to impose a priori such a restriction and estimate the correlation between the first and the second stage along with the other parameters instead of a priori assuming it equal to zero.

\subsection{Modelling framework}

Here again, more details on the modelling framework can be found in Lauer (2002). Let us call $E^{S}$ the level of general secondary education attained by an individual among $\mathrm{K}$ alternatives $E_{k}^{S}$ of increasing levels, with $k \in\{1 \ldots K\}$. Furthermore, let us define $\mathrm{K}$ variables $E^{F k}$, with $k \in\{1 \ldots K\}$, which represent the final educational level an individual attains given that he holds a secondary school degree of level $k$. 
Given his secondary school degree of level $k$, the individual may choose one of $L_{k}$ educational alternatives $E_{\ell}^{F k}$ of increasing levels, with $\ell \in\left\{1 \ldots L_{k}\right\}$. To sum up, we have the following variables:

$$
\begin{aligned}
\text { Secondary schooling: } & E^{S}=E_{k}^{S} \quad, \quad k \in\{1 \ldots K\} \\
\text { Final education: } & E^{F 1}=E_{\ell}^{F 1} \quad, \quad \ell \in\left\{1 \ldots L_{1}\right\} \\
& E^{F 2}=E_{\ell}^{F 2} \quad, \quad \ell \in\left\{1 \ldots L_{2}\right\} \\
& \ldots \\
& E^{F K}=E_{\ell}^{F K} \quad, \quad \ell \in\left\{1 \ldots L_{K}\right\}
\end{aligned}
$$

If we knew for sure that $E_{k}^{S} \mid x^{S}$ and $E_{\ell}^{F k} \mid x^{F k}$ were independent from each other, we would have $\operatorname{Pr}\left(E_{k}^{S}\left|x^{S}, E_{\ell}^{F k}\right| x^{F k}\right)=\operatorname{Pr}\left(E_{k}^{S} \mid x^{S}\right) \cdot \operatorname{Pr}\left(E_{\ell}^{F k} \mid x^{F k}\right)$ and we could estimate the equation for secondary schooling and those for final education given secondary schooling separately and in the same way as in section 3 . However, some unobserved factors might affect educational attainment both at the secondary level and at the final educational level and these equations might be correlated. If this is the case, estimating the equations separately would lead to biased estimates. Therefore, we allow the error terms to be correlated and assume that they follow a multivariate normal distribution of the following form:

$$
\left(\begin{array}{c}
\ln \varepsilon^{S} \\
\ln \varepsilon^{F 1} \\
\ln \varepsilon^{F 2} \\
\vdots \\
\ln \varepsilon^{F K}
\end{array}\right) \sim \mathcal{N}\left(\left(\begin{array}{c}
0 \\
0 \\
0 \\
\vdots \\
0
\end{array}\right),\left(\begin{array}{ccccc}
1 & \varrho_{1} & \varrho_{2} & \cdots & \varrho_{K} \\
\varrho_{1} & 1 & 0 & \cdots & 0 \\
\varrho_{2} & 0 & 1 & & \vdots \\
\vdots & \vdots & & \ddots & \vdots \\
\varrho_{K} & 0 & \cdots & 0 & 1
\end{array}\right)\right)
$$

Thus, we have $\mathrm{K}$ correlation parameters $\varrho_{k}, k \in\{1 \ldots K\}$, corresponding to the correlation between secondary school choice and final educational choice given the secondary school degree obtained, for each secondary school degree. Analogue to section 3.1, we obtain:

$$
\begin{aligned}
& \operatorname{Pr}\left(E_{k}^{S}\left|x^{S}, E_{\ell}^{F k}\right| x^{F k}\right)= \\
& \Phi_{2}\left(\gamma_{k}^{S}, \gamma_{\ell}^{F k}, \varrho_{k}\right)-\Phi_{2}\left(\gamma_{k}^{S}, \gamma_{\ell-1}^{F k}, \varrho_{k}\right)-\Phi_{2}\left(\gamma_{k-1}^{S}, \gamma_{\ell}^{F k}, \varrho_{k}\right)+\Phi_{2}\left(\gamma_{k-1}^{S}, \gamma_{\ell-1}^{F k}, \varrho_{k}\right)
\end{aligned}
$$

where $\Phi_{2}$ is the bivariate standard normal distribution and $\gamma_{k}^{S}=\mu_{k}^{S}-\beta^{S} x^{S}$ and $\gamma_{\ell}^{F k}=\mu_{\ell}^{F k}-\beta^{F k} x^{F k}$, and:

$$
\mu_{j}^{S}=\ln \left(\frac{c\left(E_{j+1}^{S}\right)-c\left(E_{j}^{S}\right)}{r\left(E_{j+1}^{S}\right)-r\left(E_{j}^{S}\right)}\right) \text { and } \mu_{j}^{F k}=\ln \left(\frac{c\left(E_{j+1}^{F k}\right)-c\left(E_{j}^{F k}\right)}{r\left(E_{j+1}^{F k}\right)-r\left(E_{j}^{F k}\right)}\right)
$$

Thus, the log-likelihood for this model may be written as:

$$
\ln \mathcal{L}=\sum_{i=1}^{n} \sum_{k=1}^{K} \sum_{\ell=1}^{L_{k}} I_{i k \ell} \ln \left[\operatorname{Pr}\left(E_{k}^{S}\left|x_{i}^{S}, E_{\ell}^{F k}\right| x_{i}^{F k}\right)\right]
$$


where $\operatorname{Pr}\left(E_{k}^{S}\left|x_{i}^{S}, E_{\ell}^{F k}\right| x_{i}^{F k}\right)$ is defined such as in equation (8) and $I_{i k \ell}$ is an indicator variable equal to 1 if individual $i$ obtained school degree $k$ and vocational degree $\ell$. The estimation of this model is not as straight-forward as that of the singleequation version in section 3 , but it remains reasonably feasible, though rather time-consuming.

\subsection{Estimation for France and Germany}

In this section, the model is applied to the GSOEP and the FQP data, the purpose being to provide an illustration of how the model functions in practice while gaining evidence on the impact of family background on educational outcomes in France and Germany. The ultimate educational outcome is, following the model, the result of two decisions: the first decision concerns attainment in general secondary education, and the second one is about post-school educational achievement. Here again, it is assumed that the educational outcome observed is the result of the decisions of the individual given some constraints.

\subsubsection{Definition of the variables}

The dependent variables are defined by the highest degree obtained in general secondary education and in post-school education given the specific school degree obtained (see synthesis in table 4). Attainment in general secondary education has been defined by three levels $E_{k}^{S}$, with $k \in\{1 \ldots 3\}$ : the lowest level $E_{1}^{S}$ is attributed to those individuals who obtained at most a degree from the Hauptschule in Germany and at most a CEP or DFEO in France. The intermediate level $E_{2}^{S}$ consists of those people holding a degree from the Realschule in Germany or the BEPC in France, and $E_{3}^{S}$ is given to individuals who obtained a degree from the highest type of general secondary school in Germany, the Gymnasium, or obtained the French Baccalauréat Général in France, thereby qualifying for university studies.

As far as post-school attainment is concerned, the definition of the dependent variable depends on the level attained in general secondary education. Since we have three possible levels of attainment in secondary education, we have three different variables $E_{\ell}^{F k}$ for post-school attainment, with $k \in\{1 \ldots 3\}$, the categories $\ell \in\left\{1 \ldots L_{k}\right\}$ of each (number and type) depending on the value of $k$, i.e. on the type of secondary school degree possessed. In the end, we estimate, through the maximisation of the log-likelihood function defined in equation (10), a model of four simultaneous equations (the secondary school equation - low, middle or high - on the one hand, and the post-low secondary, the post-middle secondary and the post-high secondary equations on the other hand), with as many correlations $\varrho_{k}, k \in\{1 \ldots 3\}$ between attainment in secondary education and subsequent achievement as there are secondary school degrees.

For those people having the lowest level of general secondary education, the dependent variable is $E_{1}^{F 1}$ if the person has no vocational degree, $E_{2}^{F 1}$ if the individual 
Table 4: Definition of dependent variables

\begin{tabular}{|c|c|c|}
\hline Education level & Germany & France \\
\hline \multicolumn{3}{|c|}{ General secondary education (equation 1): } \\
\hline$E_{1}^{S}$ Low & Hauptschule & $\mathrm{CEP} / \mathrm{DFEO}$ \\
\hline$E_{2}^{S}$ Middle & Realschule & BEPC \\
\hline$E_{3}^{S}$ High & Gymnasium & Bac Général \\
\hline \multicolumn{3}{|c|}{ Post-(general) secondary education of: } \\
\hline \multicolumn{3}{|c|}{ Low second. leavers (equation 2) } \\
\hline$E_{1}^{F 1}$ No voc. degree & No voc. degree & No voc. degree \\
\hline$E_{2}^{F 1}$ Basic voc. degree & Lehre & $\mathrm{CAP} / \mathrm{BEP}$ \\
\hline$E_{3}^{F 1}$ Interm. qualif. & Fachschule/Fachoberschule & $\mathrm{BP} /$ Bac Pro/Bac Techno \\
\hline \multicolumn{3}{|c|}{ Middle second. leavers (equation 3) } \\
\hline$E_{1}^{F^{2}}$ No voc. degree & No voc. degree & No voc. degree \\
\hline$E_{2}^{F^{2}}$ Basic voc. degree & Lehre & $\mathrm{CAP} / \mathrm{BEP}$ \\
\hline$E_{3}^{F^{2}}$ Interm. qualif. & Fachschule/Fachoberschule & BP/Bac Pro/Bac Techno \\
\hline$E_{4}^{F^{2}}$ Higher education & Fachhochschule/Uni & $B a c+2$ and beyond \\
\hline \multicolumn{3}{|c|}{ High second. leavers (equation 4) } \\
\hline$E_{1}^{F 3}$ Interm. qualif. & No higher education & No higher education \\
\hline$E_{2}^{F 3}$ Lower tertiary & Fachhochschule & $B a c+2$ \\
\hline$E_{3}^{F 3}$ Upper tertiary & $U n i$ & $B a c+3$ and beyond \\
\hline
\end{tabular}

completed a basic vocational training (like an apprenticeship or a full-time vocational school) and $E_{3}^{F 1}$ if the person has completed at least ${ }^{13}$ an advanced vocational qualification (like the Fachschule degree in Germany or the Brevet Professionnel in France, or also the vocational maturity certificate). For the group of individuals with an intermediate level of general secondary education, the dependent variable is ordered in four categories: no vocational degree $\left(E_{1}^{F 2}\right)$, a basic vocational degree $\left(E_{2}^{F 2}\right)$, an advanced vocational degree or vocational maturity certificate $\left(E_{3}^{F 2}\right)$ and a higher education degree ${ }^{14}$. Finally, the high school leavers may either have no higher education degree $\left(E_{1}^{F 3}\right)$, in which case they stopped their studies immediately after the obtention of the maturity certificate or only completed a vocational training, or hold a lower tertiary level degree $\left(E_{2}^{F 3}\right)$, or an upper tertiary level degree $\left(E_{3}^{F 3}\right)$.

One objective was to investigate whether some factors play a more important role in the first stage, other factors in the second stage of the educational career. Therefore, the same variables on family background as in section 3 (parental edu-

13 In France like in Germany, only a few individuals with the lowest level of general secondary education managed to get a higher education degree in the end (see table 8). Those who did so got access to (lower) tertiary education through the obtention of the vocational maturity certificate.

14 Generally a lower tertiary degree obtained via the obtention of the vocational maturity certificate degree. 
cation and father's occupation) have been included in all four equations. Moreover, we want to allow time-variant factors to influence educational choices. Ideally, we would like to have information on e.g. the financial situation of the household, on changes in the household structure etc. at the time when the individual decided upon his secondary education and when he decided upon his post-secondary education. Since this kind of information is not available, the approach adopted here was the following. We make the assumption that the decision concerning the next educational stage is made at the end of the immediately preceding stage. Thus, for Germany, the decision concerning secondary school choice is assumed to be made at the end of primary schooling, at the age of 10, since this is the stage at which pupils are streamed into different types of secondary schools. In France, as mentioned in section 2, pupils attend a single structure throughout lower secondary education. It is therefore assumed that the decision concerning attainment in general secondary education is made later than in Germany, at the age of 14 approximately. Therefore, we can examine the effect of the context prevailing at that time by looking at the effect of finishing primary education in that year rather than in this other year. Concretely, a set of dummy variables indicating in which year the individual finished the previous stage (primary education for Germany, lower general secondary education for France), grouped in five-year dummies has been included in the secondary school equation. Similarly, the decision concerning post-secondary education is assumed to take place at the end of secondary education. Thus, we examine the effect of finishing secondary education at a specific point in time rather than at another point in time and include in the post-school equations a set of dummy variables indicating the year in which the person finished general secondary education, grouped in five-year secondary school cohorts. The computation of the year in which the individual ended secondary education is based on information on the type of secondary education completed and its duration. This approach makes it possible to model institutional differences in the organisation of the educational stages, in particular concerning their duration. The estimation results of this system of four equations are given and commented in section 4.2.2 and 4.2.3.

\subsubsection{Determinants of secondary education}

Table 5 presents overall statistics as well as the specific results of the secondary school equation for both countries. The overall Wald test at the top of the second part of the table tests the null hypothesis that all slope coefficients of all equations are jointly insignificant. The null hypothesis is rejected at a 1 percent significance level for both countries. The specific Wald test for the secondary school equation (named here partial Wald test) is also rejected at a 1 percent significance level for France like for Germany and attests that the slope parameters of this equation are jointly significant for both countries. Gender differences in the coefficients as well as in the threshold values and in the correlations have also been tested in the same way as in section 3. Only the significant interactions with gender (at a 10 percent significance level at least, see the test results at the end of table 5) have 
been retained in the final specification, since it would be inefficient to estimate more coefficients than necessary. Likewise, the secondary school thresholds were allowed to differ for men and women, for the tests show that they differ significantly across genders (see table 5). The results of further tests on the statistical distinctness of successive threshold values show that the educational categories chosen for secondary education do not need to be aggregated neither for France nor for Germany, since the estimated thresholds are statistically different from each other, for men like for women.

Observing table 5, it appears that there has been a strong educational expansion at the secondary school level. Indeed, the primary school cohort dummies for Germany and the lower secondary cohort dummies for France all prove extremely significant for the determination of attainment in secondary education and exhibit an increasing pattern ${ }^{15}$. In other words, the later the previous stage was completed, the higher the attainment in general secondary education is, which means that the net utility of a high level secondary school degree has increased over time in both countries. The level of secondary schooling has expanded at a faster rate in France than in Germany, but there seems to have been a boom in secondary education achievement in Germany from generations finishing their primary education between 1961 and 1965 onwards $^{16}$. This is essentially due to a boom in female school achievement. Indeed, judging from the coefficients of the interaction terms, educational expansion started later on for women than for men in Germany. Until the primary school cohorts of the end of the 1950s, the increase in the utility of a higher general education used to be stronger for men. Then, however, educational expansion has been much stronger for women than for men, and the gap in the rate of expansion has increased over time. In France also, the expansion of secondary expansion has been stronger for women than for men, especially from the generations finishing lower secondary education in 1961-65 and after.

In both countries, mother's education is strongly significant for achievement at school, like father's education. Moreover, neither in France nor in Germany are there any significant differences for men and women in the effects of parental education. Roughly speaking, the coefficients have the same order of magnitude for both countries and show a similar pattern: the higher parental education is, the higher the probability is that children are successful at school. However, there is in France, contrary to Germany, an obvious threshold effect for having parents (particularly a mother) with an intermediate qualification, in particular the Baccalauréat. As a result, the positive impact on school performance of having parents (mother or father) with an intermediate qualification is significantly stronger in France than in Germany. This highlights the key role of the Baccalauréat in France. In Germany,

15 The overall impact of belonging to a specific cohort on the educational outcome is obtained by adding the coefficient of the cohort dummy to that of the interaction term between that same cohort and the gender dummy.

$16+066(=0.42+0.24)$ for this cohort, against $0.11(=0.39-0.28)$ for the previous one. 
Table 5: Determinants of secondary school attainment

\begin{tabular}{|c|c|c|c|c|}
\hline \multirow[b]{2}{*}{ Variable } & \multicolumn{2}{|c|}{ Germany } & \multicolumn{2}{|c|}{ France } \\
\hline & coef. & (s.e) & coef. & (s.e) \\
\hline \multicolumn{5}{|c|}{ End of primary $(G)$ / lower secondary $(F)$ education (ref.: 1939-1950) } \\
\hline $1951-55$ & $0.28^{* *}$ & $(0.08)$ & $0.23^{* *}$ & $(0.07)$ \\
\hline $1956-60$ & $0.39^{* *}$ & $(0.08)$ & $0.42^{* *}$ & $(0.06)$ \\
\hline $1961-65$ & $0.42^{* *}$ & $(0.08)$ & $0.52^{* *}$ & $(0.05)$ \\
\hline $1966-70$ & $0.57^{* *}$ & $(0.07)$ & $0.69^{* *}$ & $(0.05)$ \\
\hline $1971-78$ & $0.49^{* *}$ & $(0.07)$ & $0.72^{* *}$ & $(0.04)$ \\
\hline Female $* 1951-55$ & $-0.21^{\dagger}$ & $(0.11)$ & 0.02 & $(0.08)$ \\
\hline Female $* 1956-60$ & $-0.28^{*}$ & $(0.11)$ & 0.03 & $(0.07)$ \\
\hline Female $* 1961-65$ & $0.24^{*}$ & $(0.11)$ & $0.13^{*}$ & $(0.06)$ \\
\hline Female $* 1966-70$ & $0.20^{*}$ & $(0.10)$ & $0.13^{*}$ & $(0.06)$ \\
\hline Female $* 1971-78$ & $0.34^{* *}$ & $(0.10)$ & $0.31^{* *}$ & $(0.04)$ \\
\hline \multicolumn{5}{|c|}{ Mother's education (ref.: No voc. degree) } \\
\hline Basic voc. degree & $0.27^{* *}$ & $(0.04)$ & $0.20^{* *}$ & $(0.04)$ \\
\hline Intermediate qualif. & $0.42^{* *}$ & $(0.10)$ & $0.73^{* *}$ & $(0.05)$ \\
\hline Higher education & $0.85^{* *}$ & $(0.14)$ & $0.70^{* *}$ & $(0.06)$ \\
\hline Missing & 0.05 & $(0.07)$ & -0.10 & $(0.08)$ \\
\hline \multicolumn{5}{|c|}{ Father's education (ref.: No voc. degree) } \\
\hline Basic voc. degree & $0.21^{* *}$ & $(0.06)$ & $0.21^{* *}$ & $(0.03)$ \\
\hline Intermediate qualif. & $0.33^{* *}$ & $(0.07)$ & $0.63^{* *}$ & $(0.05)$ \\
\hline Higher education & $0.80^{* *}$ & $(0.09)$ & $0.87^{* *}$ & $(0.05)$ \\
\hline Missing & 0.01 & $(0.09)$ & $-0.23^{* *}$ & $(0.06)$ \\
\hline \multicolumn{5}{|c|}{ Father's occupation (ref.: Worker) } \\
\hline Farmer & 0.10 & $(0.08)$ & -0.01 & $(0.05)$ \\
\hline Self-employed & $0.65^{* *}$ & $(0.06)$ & $0.58^{* *}$ & $(0.05)$ \\
\hline Senior manager & $1.12^{* *}$ & $(0.07)$ & $1.02^{* *}$ & $(0.07)$ \\
\hline Middle manager & $0.68^{* *}$ & $(0.05)$ & $0.73^{* *}$ & $(0.05)$ \\
\hline Employee & $0.38^{* *}$ & $(0.08)$ & $0.55^{* *}$ & $(0.05)$ \\
\hline Missing & $0.28^{* *}$ & $(0.05)$ & $0.51^{* *}$ & $(0.05)$ \\
\hline Female $*$ Farmer & & & $0.24^{* *}$ & $(0.07)$ \\
\hline Female $*$ Self-employed & & & 0.11 & $(0.07)$ \\
\hline Female $*$ Senior manager & & & $-0.16^{\dagger}$ & $(0.09)$ \\
\hline Female $*$ Middle manager & & & 0.02 & $(0.07)$ \\
\hline Female $*$ Employee & & & 0.01 & $(0.07)$ \\
\hline Female $*$ Missing & & & -0.06 & $(0.06)$ \\
\hline \multicolumn{5}{|l|}{ Thresholds } \\
\hline$\mu_{1}^{S} \quad$ Male & $1.15^{* *}$ & $(0.07)$ & $1.47^{* *}$ & $(0.06)$ \\
\hline \multirow{3}{*}{$\begin{array}{ll}\mu_{2}^{S} & \text { Male } \\
& \text { Female }\end{array}$} & $1.28^{* *}$ & $(0.07)$ & $1.33^{* *}$ & $(0.05)$ \\
\hline & $2.10^{* *}$ & $(0.07)$ & $2.27^{* *}$ & $(0.06)$ \\
\hline & $2.56^{* *}$ & $(0.08)$ & $2.13^{* *}$ & $(0.05)$ \\
\hline
\end{tabular}




\begin{tabular}{lrrrr}
\hline \hline & \multicolumn{2}{c}{ Germany } & \multicolumn{2}{c}{ France } \\
Tests & $\chi^{2}$ & $\mathbf{p}>\chi^{2}$ & $\chi^{2}$ & $\mathbf{p}>\chi^{2}$ \\
\hline Tests on coefficients & & & & \\
Overall Wald test & $1,842.89$ & 0.00 & $4,432.38$ & 0.00 \\
Partial Wald tests & $1,481.89$ & 0.00 & $3,906.70$ & 0.00 \\
Female * End previous stage & 45.32 & 0.00 & 26.90 & 0.00 \\
Female * Mother's education & 2.44 & 0.68 & 0.72 & 0.95 \\
Female * Father's education & 1.03 & 0.90 & 5.84 & 0.21 \\
Female ${ }^{*}$ Father's occupation & 5.66 & 0.46 & 20.68 & 0.00 \\
Tests on thresholds & & & & \\
$\mu_{1}^{S}:$ Male $=$ Female & 4.11 & 0.04 & 3.15 & 0.08 \\
$\mu_{2}^{S}:$ Male $=$ Female & 37.19 & 0.00 & 3.85 & 0.07 \\
Males: $\mu_{1}^{S}=\mu_{2}^{S}$ & $1,001.96$ & 0.00 & $1,772.69$ & 0.00 \\
Females: $\mu_{1}^{S}=\mu_{2}^{S}$ & $1,206.35$ & 0.00 & $2,277.19$ & 0.00 \\
\hline Observations & 5,857 & 15,037 \\
Log-likelihood & $-10,021.67$ & $-25,226.79$ \\
\hline \hline Significance level : $\dagger: 10 \%$ & $*: 5 \%$ & $* *: 1 \%$ & & \\
\end{tabular}

the jump rather takes place between intermediate qualification (which is, unlike in France, often an advanced technical degree rather than a maturity certificate) and a tertiary level degree.

Father's occupation also proves to have a significant impact on children's school performance, in France like in Germany, and the coefficients follow a similar pattern. All the significant coefficients are positive, which means that individuals in the reference category, the offsprings of workers, are the least successful in terms of secondary education in both countries. Another common feature is that in both countries, sons and daughters of farmers do not have significantly better prospects at school compared to workers' offsprings ${ }^{17}$, while sons and daughters of senior managers achieve best, followed by the children of middle staff managers and of self-employed. A dissimilarity between France and Germany concerns the fact that children of French employees seem to perform comparatively better at school than their German counterparts. Another difference is that father's occupation has a slightly different impact across men and women for secondary education in France, while this is not the case in Germany: French females benefit more in terms of secondary education from having a farmer as a father and slightly less from being the daughter of a senior manager compared to males.

As far as the threshold values are concerned, the difference between France and Germany is striking. As a matter of fact, the thresholds are significantly higher for females than for males in Germany, while the reverse is true in France. This implies that for the same other characteristics and coefficients, the cost to return ratio of

17 Except for French females in France. 
completing a high level secondary school degree will be higher for women than for men, while it is higher for men than women in France, all other things equal. In other words, all else equal, achievement at school should be poorer for women than for men in Germany, while it will be better for women than for men in France. The gap in the thresholds in favour of men seems to be more pronounced in Germany than it is in France in favour of women.

\subsubsection{Determinants of post-secondary education}

The estimation results of the three post-school equations are reported in table 6 for Germany and table 7 for France. Partial Wald tests on the coefficients of each equation separately are all rejected at a 1 percent significance level and attest that the slope parameters are jointly significant in all post-school equations for both countries. For France like for Germany, however, the value of the $\chi^{2}$-statistics gets lower as the level of education gets higher. This suggests that the variables used have more explanatory power at earlier stages in the educational career, in particular at the secondary level. Here again, only the significant interactions with gender, at a 10 percent significance level at least, have been retained in the final specification and the threshold were only allowed to differ in case they prove to differ significantly for men and women (see test results in the second part of tables 6 and 7).

In France like in Germany, the educational expansion has not only concerned secondary education, but also post-secondary education, at least for those individuals with a comparatively poorer level of general secondary education. In particular, there has been a strong improvement in the subsequent educational achievement of individuals with the lowest level of general secondary education. In both countries also, this is essentially due an improvement among women, while the post-school achievement of poorly educated men has rather stagnated after an initial improvement compared to generations who finished their secondary in the decade immediately after World War II. The gender gap in favour of women in the improvement of educational attainment after no or poor school education is particularly strong in Germany, all else equal. Individuals who completed an intermediate level of general secondary education also experienced a significant improvement of their subsequent educational achievement in both countries, but there are two major differences between France and Germany. First, in France, the expansion has been similar for men and women, while the expansion has been stronger among women than among men in Germany. Second, if one compares the overall cohort coefficients, meaning that the simple cohort coefficient should be added to the gender interaction term of the corresponding cohort for Germany ${ }^{18}$, one observes that the post-BEPC educational attainment has kept improving up to the youngest generations, while that of the comparable Realschule graduates has started stagnating in Germany from the

18 Thus, the overall cohort effects compared to the reference category 1945-55 are: 0.41 for the 1956-60 cohort, 0.36 for the 1961-65 cohort, 0.83 for the 1966-70 cohort, 0.97 for the 1971-75 cohort, 0.97 for the $1976-80$ cohort and 0.87 for the 1981-86 cohort. 
generations leaving the Realschule during the 1970's and after. Interestingly, the situation is very different for high school leavers, who are entitled through the general maturity certificate to pursue tertiary level studies. In Germany, the propensity to study among those entitled to do so has declined over generations. This phenomenon starts becoming significant for those cohorts who obtained their maturity certificate

Table 6: Determinants of post-secondary school attainment - Germany

\begin{tabular}{|c|c|c|c|c|c|c|}
\hline \multirow[b]{3}{*}{ Variable } & \multicolumn{6}{|c|}{ Level of secondary school attained: } \\
\hline & \multicolumn{2}{|c|}{ Low } & \multicolumn{2}{|c|}{ Middle } & \multicolumn{2}{|c|}{ High } \\
\hline & coef. & (s.e) & coef. & $(\mathrm{s.e})$ & coef. & (s.e) \\
\hline \multicolumn{7}{|c|}{ End of secondary education (ref.: 1945-1955) } \\
\hline $1956-60$ & $0.34^{* *}$ & $(0.10)$ & $0.32^{*}$ & $(0.14)$ & 0.34 & $(0.21)$ \\
\hline $1961-65$ & $0.30^{* *}$ & $(0.10)$ & $0.38^{* *}$ & $(0.15)$ & 0.08 & $(0.20)$ \\
\hline $1966-70$ & $0.24^{*}$ & $(0.11)$ & $0.27^{\dagger}$ & $(0.16)$ & -0.09 & $(0.19)$ \\
\hline $1971-75$ & $0.23^{\dagger}$ & $(0.12)$ & $0.53^{* *}$ & $(0.14)$ & -0.28 & $(0.19)$ \\
\hline $1976-80$ & $0.36^{* *}$ & $(0.11)$ & $0.35^{*}$ & $(0.16)$ & $-0.50^{* *}$ & $(0.18)$ \\
\hline $1981-86$ & 0.19 & $(0.13)$ & 0.20 & $(0.15)$ & $-0.68^{* *}$ & $(0.17)$ \\
\hline Female * $1956-60$ & $0.28^{\dagger}$ & $(0.15)$ & 0.09 & $(0.20)$ & & \\
\hline Female * 1961-65 & $0.29^{\dagger}$ & $(0.15)$ & -0.02 & $(0.22)$ & & \\
\hline Female $* 1966-70$ & $0.79^{* *}$ & $(0.15)$ & $0.56^{* *}$ & $(0.22)$ & & \\
\hline Female * 1971-75 & $0.57^{* *}$ & $(0.15)$ & $0.44^{*}$ & $(0.19)$ & & \\
\hline Female * $1976-80$ & $0.69^{* *}$ & $(0.14)$ & $0.62^{* *}$ & $(0.19)$ & & \\
\hline Female * 1981-86 & $0.79^{* *}$ & $(0.18)$ & $0.62^{* *}$ & $(0.18)$ & & \\
\hline \multicolumn{7}{|c|}{ Mother's education (ref.: No voc. degree) } \\
\hline Basic voc. degree & $0.26^{* *}$ & $(0.05)$ & $0.24^{* *}$ & $(0.06)$ & -0.08 & $(0.08)$ \\
\hline Intermediate qualif. & $0.47^{* *}$ & $(0.15)$ & $0.52^{* *}$ & $(0.12)$ & -0.17 & $(0.15)$ \\
\hline Higher education & & & & & $0.09^{*}$ & $(0.04)$ \\
\hline Missing & 0.00 & $(0.07)$ & $0.20^{\dagger}$ & $(0.10)$ & 0.00 & $(0.18)$ \\
\hline \multicolumn{7}{|c|}{ Father's education (ref.: No voc. degree) } \\
\hline Basic voc. degree & $0.20^{* *}$ & $(0.08)$ & $0.17^{\dagger}$ & $(0.09)$ & 0.06 & $(0.14)$ \\
\hline Intermediate qualif. & $0.54^{* *}$ & $(0.12)$ & $0.28^{*}$ & $(0.11)$ & $0.09^{*}$ & $(0.03)$ \\
\hline Higher education & $1.20^{* *}$ & $(0.25)$ & $0.70^{* *}$ & $(0.16)$ & $0.41^{*}$ & $(0.19)$ \\
\hline Missing & 0.13 & $(0.11)$ & -0.02 & $(0.13)$ & $-0.46^{*}$ & $(0.22)$ \\
\hline Female ${ }^{*}$ Basic voc. degree & $0.29^{* *}$ & $(0.10)$ & & & & \\
\hline Female * Interm. qualif. & 0.10 & $(0.15)$ & & & & \\
\hline Female $*$ Higher educ. & -0.24 & $(0.30)$ & & & & \\
\hline Female * Missing & 0.19 & $(0.13)$ & & & & \\
\hline \multicolumn{7}{|c|}{ Father's occupation (ref.: Worker) } \\
\hline Farmer & 0.12 & $(0.08)$ & $0.38^{* *}$ & $(0.14)$ & 0.03 & $(0.19)$ \\
\hline Self-employed & $0.50^{* *}$ & $(0.09)$ & $0.46^{* *}$ & $(0.12)$ & $0.32^{*}$ & $(0.15)$ \\
\hline Senior manager & $0.68^{* *}$ & $(0.16)$ & $0.87^{* *}$ & $(0.17)$ & $0.39^{*}$ & $(0.16)$ \\
\hline Middle manager & $0.51^{* *}$ & $(0.08)$ & $0.53^{* *}$ & $(0.11)$ & 0.21 & $(0.14)$ \\
\hline Employee & $0.32^{* *}$ & $(0.10)$ & $0.39^{* *}$ & $(0.11)$ & 0.16 & $(0.19)$ \\
\hline Missing & $0.10^{\dagger}$ & $(0.06)$ & $0.19^{*}$ & $(0.08)$ & 0.07 & $(0.12)$ \\
\hline
\end{tabular}




\begin{tabular}{|c|c|c|c|c|c|c|c|}
\hline & & \multicolumn{6}{|c|}{ Level of secondary school attained: } \\
\hline & & \multicolumn{2}{|c|}{ Low } & \multicolumn{2}{|c|}{ Middle } & \multicolumn{2}{|c|}{ High } \\
\hline & & coef. & $(\mathrm{s.e})$ & coef. & (s.e) & coef. & (s.e) \\
\hline \multicolumn{2}{|c|}{ Thresholds } & \multicolumn{2}{|c|}{$k=1$} & \multicolumn{2}{|c|}{$k=2$} & \multicolumn{2}{|c|}{$k=3$} \\
\hline \multirow{2}{*}{$\mu_{1}^{F k}$} & Male & $-0.69^{* *}$ & $(0.08)$ & -0.28 & $(0.57)$ & $2.31^{* *}$ & $(0.33)$ \\
\hline & Female & $0.41^{* *}$ & $(0.09)$ & $0.56^{*}$ & $(0.32)$ & $2.47^{* *}$ & $(0.28)$ \\
\hline \multirow[t]{2}{*}{$\mu_{2}^{F k}$} & Male & $1.15^{* *}$ & $(0.14)$ & $1.00^{* *}$ & $(0.32)$ & $2.49^{* *}$ & $(0.35)$ \\
\hline & Female & $2.27^{* *}$ & $(0.21)$ & $1.89^{* *}$ & $(0.24)$ & $2.74^{* *}$ & $(0.30)$ \\
\hline \multirow{2}{*}{$\mu_{3}^{F k}$} & Male & & & $1.82^{* *}$ & $(0.18)$ & & \\
\hline & Female & & & $2.74^{* *}$ & $(0.14)$ & & \\
\hline \multirow{2}{*}{\multicolumn{2}{|c|}{$\begin{array}{l}\text { Corr. second./post-second. } \\
\varrho_{k}\end{array}$}} & \multicolumn{2}{|c|}{$k=1$} & \multicolumn{2}{|c|}{$k=2$} & \multicolumn{2}{|c|}{$k=3$} \\
\hline & & $0.64^{* *}$ & $(0.15)$ & $0.70^{* *}$ & $(0.18)$ & $0.86^{* *}$ & $(0.10)$ \\
\hline Tests & & $\chi^{2}$ & $\mathbf{p}>\chi^{2}$ & $\chi^{2}$ & $\mathbf{p}>\chi^{2}$ & $\chi^{2}$ & $\mathbf{p}>\chi^{2}$ \\
\hline \multicolumn{8}{|c|}{ Tests on coefficients } \\
\hline \multicolumn{2}{|c|}{ Partial Wald tests } & 369.15 & 0.00 & 126.77 & 0.00 & 159.71 & 0.00 \\
\hline \multicolumn{2}{|c|}{ Female $*$ End prev. stage } & 35.03 & 0.00 & 12.04 & 0.10 & 9.61 & 0.21 \\
\hline \multicolumn{2}{|c|}{ Female * Mother's educ. } & 2.63 & 0.45 & 4.62 & 0.20 & 2.04 & 0.73 \\
\hline \multicolumn{2}{|c|}{ Female ${ }^{*}$ Father's educ. } & 9.44 & 0.01 & 4.86 & 0.30 & 3.32 & 0.51 \\
\hline \multicolumn{2}{|c|}{ Female * Father's occ. } & 10.31 & 0.19 & 1.85 & 0.93 & 2.81 & 0.83 \\
\hline \multicolumn{2}{|c|}{ Tests on thresholds } & \multicolumn{2}{|c|}{$k=1$} & \multicolumn{2}{|c|}{$k=2$} & \multicolumn{2}{|c|}{$k=3$} \\
\hline \multirow{3}{*}{\multicolumn{2}{|c|}{$\begin{array}{l}\mu_{1}^{F k}: \text { Male }=\text { Female } \\
\mu_{2}^{F k}: \text { Male }=\text { Female } \\
\mu_{3}^{F k}: \text { Male }=\text { Female }\end{array}$}} & 77.91 & 0.00 & 24.97 & 0.00 & 4.76 & 0.11 \\
\hline & & 57.00 & 0.00 & 36.39 & 0.00 & 2.24 & 0.03 \\
\hline & & & & 38.61 & 0.00 & & \\
\hline \multirow[t]{2}{*}{ Males: } & $\mu_{1}^{F k}=\mu_{2}^{F k}$ & 215.99 & 0.00 & 22.72 & 0.00 & 31.04 & 0.00 \\
\hline & $\mu_{2}^{F k}=\mu_{3}^{F k}$ & & & 23.39 & 0.00 & & \\
\hline \multirow[t]{2}{*}{ Females: } & $\mu_{1}^{F k}=\mu_{2}^{F k}$ & 144.64 & 0.00 & 28.83 & 0.00 & 18.81 & 0.00 \\
\hline & $\mu_{2}^{F k}=\mu_{3}^{F k}$ & & & 27.69 & 0.00 & & \\
\hline \multirow{2}{*}{\multicolumn{2}{|c|}{$\begin{array}{l}\text { Tests on correlations } \\
\varrho_{k}: \text { Male }=\text { Female }\end{array}$}} & \multicolumn{2}{|c|}{$k=1$} & \multicolumn{2}{|c|}{$k=2$} & $k=$ & \\
\hline & & 0.30 & 0.58 & 0.45 & 0.50 & 0.05 & 0.82 \\
\hline
\end{tabular}

Significance level : $\nmid: 10 \% \quad *: 5 \% \quad * *: 1 \%$

from the middle of the 1970s onwards and is true for both men and women. In France, however, a similar phenomenon of declining propensity to study is observable among men, though to a lesser extent, but among female Baccalauréat holders, there has been, on the contrary, an increase in the propensity to pursue tertiary level studies over time.

Parental education continues to exert an influence at the level of post-school education, though to a lesser extent than for secondary schooling. Here again, the pattern is very similar for France and Germany. In both countries, mother's educa- 
Table 7: Determinants of post-secondary school attainment - France

\begin{tabular}{|c|c|c|c|c|c|c|}
\hline \multirow[b]{3}{*}{ Variable } & \multicolumn{6}{|c|}{ Level of secondary school attained: } \\
\hline & \multicolumn{2}{|c|}{ Low } & \multicolumn{2}{|c|}{ Middle } & \multicolumn{2}{|c|}{ High } \\
\hline & coef. & $(\mathrm{s.e})$ & coef. & (s.e) & coef. & (s.e) \\
\hline \multicolumn{7}{|c|}{ End of secondary education (ref.: 1945-1955) } \\
\hline $1956-60$ & $0.42^{* *}$ & $(0.06)$ & $0.32^{* *}$ & $(0.11)$ & 0.00 & $(0.17)$ \\
\hline $1961-65$ & $0.42^{* *}$ & $(0.06)$ & $0.39^{* *}$ & $(0.10)$ & -0.16 & $(0.17)$ \\
\hline $1966-70$ & $0.39^{* *}$ & $(0.06)$ & $0.50^{* *}$ & $(0.11)$ & -0.07 & $(0.19)$ \\
\hline $1971-75$ & $0.43^{* *}$ & $(0.07)$ & $0.69^{* *}$ & $(0.12)$ & $-0.36^{\dagger}$ & $(0.20)$ \\
\hline $1976-80$ & $0.42^{* *}$ & $(0.07)$ & $0.75^{* *}$ & $(0.12)$ & $-0.36^{\dagger}$ & $(0.21)$ \\
\hline $1981-86$ & $0.39^{* *}$ & $(0.08)$ & $0.91^{* *}$ & $(0.12)$ & $-0.40^{\dagger}$ & $(0.21)$ \\
\hline Female $* 1956-60$ & -0.11 & $(0.09)$ & & & 0.21 & $(0.23)$ \\
\hline Female $* 1961-65$ & $0.17^{*}$ & $(0.08)$ & & & 0.28 & $(0.21)$ \\
\hline Female $* 1966-70$ & $0.26^{* *}$ & $(0.08)$ & & & 0.33 & $(0.21)$ \\
\hline Female $* 1971-75$ & $0.19^{*}$ & $(0.09)$ & & & $0.49^{*}$ & $(0.22)$ \\
\hline Female $* 1976-80$ & $0.39^{* *}$ & $(0.10)$ & & & $0.47^{*}$ & $(0.23)$ \\
\hline Female $* 1981-86$ & $0.59^{* *}$ & $(0.11)$ & & & $0.61^{* *}$ & $(0.23)$ \\
\hline \multicolumn{7}{|c|}{ Mother's education (ref.: No voc. degree) } \\
\hline Basic voc. degree & $0.24^{* *}$ & $(0.08)$ & $0.17^{*}$ & $(0.07)$ & 0.02 & $(0.10)$ \\
\hline Intermediate qualif. & 0.15 & $(0.15)$ & $0.29^{*}$ & $(0.12)$ & 0.10 & $(0.19)$ \\
\hline Higher education & & & & & $0.10^{*}$ & $(0.18)$ \\
\hline Missing & 0.00 & $(0.11)$ & 0.02 & $(0.17)$ & -0.11 & $(0.20)$ \\
\hline Female $^{*}$ Basic voc. degree & 0.11 & $(0.12)$ & & & & \\
\hline Female ${ }^{*}$ Interm. & $0.57^{* *}$ & $(0.18)$ & & & & \\
\hline Female ${ }^{*}$ Higher education & & & & & & \\
\hline Female $*$ Missing & -0.10 & $(0.17)$ & & & & \\
\hline \multicolumn{7}{|c|}{ Father's education (ref.: No voc. degree) } \\
\hline Basic voc. degree & $0.36^{* *}$ & $(0.04)$ & $0.16^{* *}$ & $(0.06)$ & 0.10 & $(0.11)$ \\
\hline Intermediate qualif. & $0.37^{* *}$ & $(0.10)$ & $0.35^{* *}$ & $(0.11)$ & $0.12^{*}$ & $(0.19)$ \\
\hline Higher education & $0.60^{* *}$ & $(0.14)$ & $0.46^{* *}$ & $(0.15)$ & $0.31^{*}$ & $(0.25)$ \\
\hline Missing & $-0.23^{* *}$ & $(0.07)$ & -0.17 & $(0.12)$ & -0.24 & $(0.19)$ \\
\hline \multicolumn{7}{|c|}{ Father's occupation (ref.: Worker) } \\
\hline Farmer & $-0.18^{* *}$ & $(0.05)$ & $0.22^{* *}$ & $(0.07)$ & 0.11 & $(0.12)$ \\
\hline Self-employed & $0.36^{* *}$ & $(0.07)$ & $0.22^{*}$ & $(0.10)$ & 0.06 & $(0.22)$ \\
\hline Senior manager & $0.55^{* *}$ & $(0.15)$ & $0.47^{* *}$ & $(0.14)$ & $0.30^{* *}$ & $(0.29)$ \\
\hline Middle manager & $0.36^{* *}$ & $(0.09)$ & $0.28^{*}$ & $(0.11)$ & 0.08 & $(0.24)$ \\
\hline Employee & $0.43^{* *}$ & $(0.07)$ & 0.16 & $(0.10)$ & 0.02 & $(0.20)$ \\
\hline Missing & $0.16^{*}$ & $(0.07)$ & $0.24^{* *}$ & $(0.09)$ & $0.43^{*}$ & $(0.20)$ \\
\hline Female $*$ Farmer & $0.18^{*}$ & $(0.08)$ & & & & \\
\hline Female $*$ Self-employed & $0.22^{*}$ & $(0.09)$ & & & & \\
\hline Female $*$ Senior manager & 0.09 & $(0.17)$ & & & & \\
\hline Female * Middle manager & $0.31^{* *}$ & $(0.11)$ & & & & \\
\hline Female $*$ Employee & 0.08 & $(0.10)$ & & & & \\
\hline Female * Missing & $0.22^{* *}$ & $(0.08)$ & & & & \\
\hline
\end{tabular}




\begin{tabular}{|c|c|c|c|c|c|c|c|}
\hline & \multicolumn{6}{|c|}{ Level of secondary school attained: } \\
\hline & & \multicolumn{2}{|c|}{ Low } & \multicolumn{2}{|c|}{ Middle } & \multicolumn{2}{|c|}{ High } \\
\hline & & coef. & (s.e) & coef. & (s.e) & coef. & (s.e) \\
\hline \multicolumn{2}{|c|}{ Thresholds } & \multicolumn{2}{|c|}{$k=1$} & \multicolumn{2}{|c|}{$k=2$} & \multicolumn{2}{|c|}{$k=3$} \\
\hline \multirow[t]{2}{*}{$\mu_{1}^{F k}$} & Male & $0.41^{* *}$ & $(0.05)$ & \multirow{2}{*}{$0.69^{* *}$} & \multirow{2}{*}{$(0.24)$} & $0.34^{* *}$ & $(0.13)$ \\
\hline & Female & $1.07^{* *}$ & $(0.07)$ & & & $0.96^{* *}$ & $(0.13)$ \\
\hline \multirow{2}{*}{$\mu_{2}^{F k}$} & Male & $1.91^{* *}$ & $(0.10)$ & \multirow{2}{*}{$1.53^{* *}$} & \multirow{2}{*}{$(0.21)$} & $0.92^{* *}$ & $(0.13)$ \\
\hline & Female & $2.39^{* *}$ & $(0.12)$ & & & $1.82^{* *}$ & $(0.13)$ \\
\hline$\mu_{3}^{F k}$ & $\begin{array}{l}\text { Male } \\
\text { Female }\end{array}$ & & & $2.18^{* *}$ & $(0.19)$ & & \\
\hline \multirow{2}{*}{\multicolumn{2}{|c|}{$\begin{array}{l}\text { Corr. second./post-second. } \\
\varrho_{k}\end{array}$}} & \multicolumn{2}{|c|}{$k=1$} & \multicolumn{2}{|c|}{$k=2$} & \multicolumn{2}{|c|}{$k=3$} \\
\hline & & $0.39^{*}$ & $(0.16)$ & $0.24^{\dagger}$ & $(0.14)$ & $0.10^{\dagger}$ & $(0.06)$ \\
\hline Tests & & $\chi^{2}$ & $\mathbf{p}>\chi^{2}$ & $\chi^{2}$ & $\mathbf{p}>\chi^{2}$ & $\chi^{2}$ & $\mathbf{p}>\chi^{2}$ \\
\hline \multicolumn{8}{|c|}{ Tests on coefficients } \\
\hline \multicolumn{2}{|c|}{ Partial Wald tests } & 429.17 & 0.00 & 113.95 & 0.00 & 87.00 & 0.00 \\
\hline \multicolumn{2}{|c|}{ Female $*$ End prev. stage } & 39.62 & 0.00 & 6.20 & 0.40 & 16.15 & 0.01 \\
\hline \multicolumn{2}{|c|}{ Female ${ }^{*}$ Mother's educ. } & 8.98 & 0.03 & 4.06 & 0.26 & 4.50 & 0.34 \\
\hline \multirow{2}{*}{\multicolumn{2}{|c|}{$\begin{array}{l}\text { Female * Father's educ. } \\
\text { Female * Father's occ. }\end{array}$}} & 4.06 & 0.25 & 4.29 & 0.37 & 1.34 & 0.85 \\
\hline & & 13.68 & 0.03 & 5.69 & 0.46 & 3.64 & 0.73 \\
\hline \multicolumn{2}{|c|}{ Tests on thresholds } & \multicolumn{2}{|c|}{$k=1$} & \multicolumn{2}{|c|}{$k=2$} & \multicolumn{2}{|c|}{$k=3$} \\
\hline \multirow{3}{*}{\multicolumn{2}{|c|}{$\begin{array}{l}\mu_{1}^{F k}: \text { Male }=\text { Female } \\
\mu_{2}^{F k}: \text { Male }=\text { Female } \\
\mu_{3}^{F k}: \text { Male }=\text { Female }\end{array}$}} & 109.66 & 0.00 & 0.29 & 0.59 & 14.67 & 0.00 \\
\hline & & 39.05 & 0.00 & 0.11 & 0.73 & 30.63 & 0.00 \\
\hline & & & & 0.05 & 0.83 & & \\
\hline Males: & $\begin{array}{l}\mu_{1}^{F k}=\mu_{2}^{F k} \\
\mu_{2}^{F k}=\mu_{3}^{F k}\end{array}$ & $2,281.42$ & 0.00 & $\begin{array}{r}1,363.11 \\
696.48\end{array}$ & $\begin{array}{l}0.00 \\
0.00\end{array}$ & 291.34 & 0.00 \\
\hline Females: & $\mu_{1}^{F k}=\mu_{2}^{F k}$ & $1,294.06$ & 0.00 & $1,363.11$ & 0.00 & 560.95 & 0.00 \\
\hline & $\mu_{2}^{F k}=\mu_{3}^{F k}$ & & & 696.48 & 0.00 & & \\
\hline Tests on & correlations & $k=$ & & $k=$ & & & \\
\hline$\varrho_{k}:$ Male & $=$ Female & 3.45 & 0.18 & 0.96 & 0.32 & 0.86 & 0.35 \\
\hline
\end{tabular}

tion $^{19}$ plays a less important role compared to father's education at the post-school level, though it remains significant. Having a university graduate as a father is particularly discriminating for the post-school educational prospects of individual with low or intermediate general qualification, especially for Hauptschule leavers in Germany. At a higher level of secondary education, however, the influence of parental education attenuates strongly. Mother's education has virtually no influence on the educational decisions of general maturity holders, except if she is a university gra-

19 The too small proportion of mothers with a higher education degree made it necessary to aggregate the categories "intermediate qualification" and "higher education" into one single category for the post-school attainment of people with low of middle general education. 
duate, but even there, the effect is very small in scope. The educational attainment of the father has more influence on the probability to undertake tertiary level studies, but the effect is weaker than for those individuals with a general education below the maturity level. The interaction terms in the post-low secondary equation show that the educational attainment of the father seems to have more importance for women: the fact that the father has completed an apprenticeship (in Germany) or an intermediate qualification (in France) improves more the prospects in vocational education for females than for males. However, the other interaction terms are not significant in statistical terms.

In France like in Germany, the effect of father's occupational position is strongest for secondary education, and tends to decrease as the education level already attained gets higher (with the exception of Realschule leavers in Germany, for which the impact of father's occupation is still particularly strong). The impact of father's occupation is weakest for holders of the maturity certificate. In this group, only individuals with a senior manager (or a self-employed in Germany) as a father achieve significantly better than the reference category of workers' offsprings. Overall, in both countries, like for secondary schooling, sons and daughters of senior managers have undoubtedly the best educational prospects with respect to post-school education, while workers' offsprings have the worst educational outcomes. Also children of middle staff managers and of self-employed achieve significantly better than workers' offsprings. It is worth noticing that self-employment seems to have a somewhat stronger positive impact in Germany than in France, especially at higher education levels (achievement after middle or high secondary education). Children of farmers perform better at the post-school level if they succeed in having an intermediate level of general education ${ }^{20}$. There are no differences between men and women with respect to the impact of father's occupation in Germany, whatever the educational stage observed, and only slight differences in France for secondary education and post-CEP/DFEO education ${ }^{21}$.

At the post-secondary level, the thresholds are higher for women than for men in both countries, which implies that French women have only an advantage in terms of cost to return ratio as far as general education is concerned. For vocational education, however, men are in a better position, like in Germany. A noticeable difference between France and Germany is that there are no differences across genders in the thresholds for post-school attainment of BEPC holders. On the other hand, however, the gender gap in favour of men among holders of the general maturity certificate seem to be more pronounced in France than in Germany.

20 The negative impact of having a farmer as a father found for the further education of men with no or only a poor school degree in France is compensated by a positive impact of the same extent for women.

21 As mentioned previously, French females benefit more from having a farmer as a father, but also from having a self-employed father of middle staff manager as far as their post-school education (low level) is concerned. 
In France and in Germany alike, there are no significant differences between males and females in the correlation between secondary school attainment and postsecondary achievement. Therefore, only one single correlation coefficient has finally been estimated in both countries. Interestingly, even with this rather simple specification in terms of variables included, the correlations between the secondary school equation and the post-secondary equations all prove significant for both countries ${ }^{22}$. This implies that the decisions at the different stages are not independent and that a purely sequential model - or a model focussing on one specific transition within the educational career in isolation from previous transitions - would be inappropriate. Therefore, the additional computational burden resulting from a time-intensive maximisation procedure seems to be worth it ${ }^{23}$. Secondary and post-secondary attainments seem to be more closely related in Germany than in France, both in terms of the size of the correlation than in terms of significance of the correlations ${ }^{24}$.

\section{Summary and conclusions}

This paper aimed at analysing whether the differences in the distribution of educational attainment in France and Germany have their origin in a different impact of certain factors on educational achievement in either countries. The empirical analysis is an application of a theoretical model of educational attainment developed for this purpose and based on the human capital theory. The principle of this model is that there is a finite number of possible educational alternatives which may be ordered by level. Each educational alternative yields a certain utility to the individual. The net utility of a specific educational alternative is expressed in terms of the difference between the "returns" and the "costs" associated with this alternative for each individual. The individual chooses, given his specific constraints or characteristics, to attain the education level which maximises his net utility.

In its simplest version, the formalisation of these assumptions leads to an ordered probit model where the threshold values are given by the expected ratio of the marginal costs to the marginal returns. In other words, the individual assesses the additional cost of attaining the next higher education level and the additional return of doing so, and if the ratio of the former to the latter, given his characteristics, is below a certain threshold, he will opt for the next higher level. An advantage in practical terms is that it is not necessary to have a precise estimation of the costs and of the returns, but it is enough to dispose of variables which exert an influence on the perceived cost to return ratio. We can therefore apply the model to the

22 A speculation of the sign of the correlation between the error terms of the different would be too hazardous since we do not know exactly what these unobserved factors are.

23 If the correlations had proved to be insignificant, the estimations should rather be run separately, because it would be more efficient in the sense that fewer parameters are estimated.

24 This is not really surprising if one considers that the sequences defined by the model depict very well the German education system, while the stages within the French education system are more loosely interrelated and more reorientations are possible. 
analysis of the impact of social origin, birth cohort and gender on the thresholds and consequently on educational attainment, measured by the highest degree obtained, in France and Germany, on the basis of the GSOEP data for Germany and FQP data for France.

To sum up the results, there are surprisingly few differences in the impact of family background on ultimate educational outcomes in France and Germany. In both countries, the higher the education of the parents is, the higher the educational outcome of their children are. Also the impact of father's occupational position is very similar. Children of senior managers have the best educational prospects while workers' offsprings face the worst educational outcomes. In both countries also, the impact of parental background does not differ across genders. However, there are some differences between France and Germany with respect to the path of educational expansion for men and women, but also with respect to the threshold values. Indeed, an originality of the ordered probit estimated here is that the threshold values have been allowed to differ between men and women. This proved particularly useful, since in both countries, women prove to have systematically higher educational thresholds than men, which means that access to education is more difficult for women than for men, all other things equal. However, women's handicap turns out to be much larger in Germany than in France.

In a second step, the study explores the process of educational achievement into more detail. The ultimate educational outcome is decomposed into two stages: achievement at school and post-school education given the school degree obtained. The model is extended in such a way that the same utility maximisation framework as described above applies at both stages, but a correlation between the two stages is permitted and estimated along with the other parameters. In practical terms, the empirical application of the model boils down to estimating a multivariate ordered probit, where we have one equation for secondary education and as many postsecondary education equations as there are secondary school degrees. Here again, the model could be directly applied to the case of France and Germany. In addition to the usual family background variables, a set of dummy variables has been added which indicates the year at which the individual finished the previous educational stage. Indeed, it is assumed that individuals decide in the last year of the previous stage on their education for the next stage. This approach makes it possible to model institutional differences in the organisation of the educational stages, in particular with respect to their duration.

The estimation results show that there is indeed a significant correlation between school and post-school attainment, which justifies the computational burden of the simultaneous estimation. The correlation does not differ significantly across genders in neither country. However, many of the explanatory variables prove to exert a different influence depending on the educational stage observed. The educational upgrade phenomenon across cohorts, for instance, occurred at the secondary level, as well as at the post-secondary level for those level with a comparatively poorer 
level of general secondary education, but not for post-school education of maturity holders, who have, on the contrary, experienced a decline in their propensity to undertake tertiary level studies. In this, matter, France and Germany differ, since the decline mentioned only concerns men in France, while the subsequent educational attainment of French female maturity holders - contrary to their German counterparts - has increased over time. As far as parental background is concerned, France and Germany prove surprisingly similar. Parental education seems to play a more important role for secondary than for post-secondary education. Nevertheless, the key role of Baccalauréat appears by way of a stronger positive effect of parents with an intermediate qualification in France at the secondary level. In both countries, the influence of parental education attenuates strongly for maturity holders, especially mother's education. Only children of university graduates seem to have a significant advantage at this level. Also the influence of father's occupation exhibit a more or less similar pattern in France and Germany, with, at the school like at the post school level, a significantly better educational achievement of children of senior managers, while worker's offsprings have the worst educational prospects. However, as far as the threshold values are concerned, the difference between France and Germany is striking. Indeed, at the secondary level, the thresholds are significantly higher for women than for men in Germany, while the reverse is true in France. This means that in Germany, men achieve better than women at school, whereas in France, women do better at school than men, all other things equal. At the post-secondary level, however, French women have, like German women, higher thresholds than men, which means that they are at a disadvantage, except for the group of individual with a school degree of intermediate level (BEPC), for which there are no significant differences between men and women.

Thus, in spite of substantial differences in the organisation of the education as well as in the distribution of educational attainment in France and Germany, both countries prove surprisingly similar with respect to the impact of family background as well as cohort effects on educational attainment, even though slight differences appear in specific areas like for instance gender differences. Moreover, it proved worth it to look into more detail in the educational prospect, since some of the factors observed proved to exert a different influence at the school level and at the post-secondary level. The model that has been developed proved particularly useful for this purpose. 


\section{References}

Amemiya, T. (1986). Advanced Econometrics (1985 ed.). Oxford: Basil Blackwell Ltd.

Blossfeld, H.-P. (1993). Changes in Educational Opportunities in the Federal Republic of Germany. In Y. Shavit and H.-P. Blossfeld (Eds.), Persistent Inequality. Changing Educational Attainment in Thirteen Countries. Boulder: Westview Press.

Boudon, R. (1973). L’inégalité des chances. Paris: Armand Colin.

Bourdieu, P. and Passeron, J. (1970). La reproduction. Paris: Les éditions de Minuit.

Cameron, S. V. and Heckman, J. J. (1998). Life Cycle Schooling and Dynamic Selection Bias: Models and Evidence for Five Cohorts of American Males. Journal of Political Economy, 106(2), 262-333.

Dustmann, C. (2001). Parental Background, Primary to Secondary School Transition and Wages (Discussion Paper No. 367). IZA.

Gould, W. and Sribney, W. (1999). Maximum likelihood estimation with Stata. College Station: Stata Press.

Gouriéroux, C. (1989). Econométrie des variables qualitatives (2 ed.). Paris: Economica.

Goux, D. and Maurin, E. (1997). Destinées sociales: le rôle de l'école et du milieu d'origine. Economie et Statistique, 306 (6), 13-26.

Haisken-DeNew, J. and Frick, J. (2000). Desktop Companion to the German SocioEconomic Panel (GSOEP) Study. Berlin.

Kristen, C. (1999). Bildungsentscheidungen und Bildungsungleichheit - ein Überblick über den Forschungsstand (Arbeitspapier No. 5). MZES.

Lauer, C. (2001). Educational Attainment: A French-German Comparison (Documentation No. 01-02). ZEW.

Lauer, C. (2002). A Model of Educational Attainment-Application to the German Case (Discussion Paper No. 02-06). ZEW.

Maddala, G. S. (1983). Limited-dependent and qualitative variables in econometrics. Cambridge: Cambridge University Press.

Müller, W. and Haun, D. (1994). Bildungsexpansion und Bildungsungleichheit. In W. Glatzer (Ed.), Einstellungen und Lebensbedingungen in Europa (p. 225268). Frankfurt: Campus. 
OECD. (2000). Education at a Glance: OECD Indicators (2000 ed.). Paris: Organisation for Economic Co-operation and Development.

Rosenzweig, M. R. and Wolpin, K. I. (1993). Intergenerational Support and the LifeCycle Incomes of Young Men and their Parents: Human Capital Investments, Coresidence and Intergenerational Financial Transfers. Journal of Labor Economics, 11(1), 84-112.

Thélot, C. and Vallet, L.-A. (2000). La réduction des inégalités sociales devant l'école depuis le début du siècle. Economie et Statistique, 334, 3-32. 


\section{Appendix}

\section{Data sets}

The GSOEP. The German Socio-Economic Panel (GSOEP) is a longitudinal household survey conducted on an annual basis since 1984. In the first wave, some 12,000 individuals aged 16 and over, and distributed across roughly 6,000 households, were interviewed. The information available is drawn from the statements of the individuals. Individual and household identifiers make it possible to track individuals over time. Due to panel attrition, sample size reduces somewhat each year, but in 1998, a refreshment sample of about 2,000 persons has been added to the data base and in 2000, another sample of about 11,000 new individuals has been included. Initially, the sample only referred to residents in West Germany, but following German unification, the sample was extended to the former German Democratic Republic in 1990. The GSOEP is representative of the population residing in Germany and contains a large number of socio-economic variables on demography, education, employment, income, housing and health. For further information on the GSOEP, see Haisken-DeNew and Frick (2000).

The FQP Survey. The Formation et Qualification Professionnelles (FQP) Survey is a cross-sectional survey which was drawn for the years 1964, 1970, 1977, 1985 and 1993. Only the 1993 wave is available for this research. This wave covers about 18,000 individuals age between 20 and 64 and distributed across 14,000 households. The FQP survey contains detailed information on the current and past labour market situation of the individuals, very detailed information on their education and training as well as on their family background. For further information on the FQP Survey, consult the online information available under http://www.iresco.fr/labos/lasmas/ enqfqp.htm. 
Table 8: Descriptive statistics for the sample of the simultaneous estimation

\begin{tabular}{|c|c|c|c|}
\hline & Variable & $\begin{array}{c}\text { Germany } \\
(\%)\end{array}$ & $\begin{array}{c}\text { France } \\
(\%)\end{array}$ \\
\hline \multirow{3}{*}{ Secondary education } & Low & 56.95 & 59.88 \\
\hline & Middle & 27.74 & 17.98 \\
\hline & High & 15.32 & 22.14 \\
\hline \multirow[t]{5}{*}{ Final education } & No vocational degree & 24.07 & 45.80 \\
\hline & Basic voc. degree & 45.42 & 26.78 \\
\hline & Intermediate qualif. & 17.15 & 10.73 \\
\hline & Lower tertiary & 4.26 & 7.59 \\
\hline & Upper tertiary & 9.09 & 9.09 \\
\hline \multicolumn{4}{|l|}{ Post-school education of: } \\
\hline \multirow[t]{4}{*}{ Low second. leavers } & No vocational degree & 27.82 & 62.55 \\
\hline & Basic voc. degree & 60.60 & 32.94 \\
\hline & Intermediate qualif. & 10.28 & 3.35 \\
\hline & Higher education & 1.31 & 1.06 \\
\hline \multirow[t]{4}{*}{ Middle second. leavers } & No vocational degree & 8.05 & 37.71 \\
\hline & Basic voc. degree & 46.55 & 31.87 \\
\hline & Intermediate qualif. & 32.44 & 18.37 \\
\hline & Higher education & 12.96 & 12.05 \\
\hline \multirow[t]{3}{*}{ High second. leavers } & No higher education & 28.08 & 34.27 \\
\hline & Lower tertiary & 9.03 & 26.47 \\
\hline & Upper tertiary & 62.89 & 39.26 \\
\hline \multirow[t]{2}{*}{ Sex } & Male & 50.04 & 49.07 \\
\hline & Female & 49.96 & 50.93 \\
\hline \multirow[t]{4}{*}{ Birth cohort } & 1929-38 & 22.95 & 19.95 \\
\hline & $1939-48$ & 23.75 & 22.10 \\
\hline & $1949-58$ & 23.07 & 28.95 \\
\hline & 1959-68 & 30.23 & 29.00 \\
\hline \multirow{7}{*}{$\begin{array}{l}\text { End of primary }(G) / \text { lower } \\
\text { secondary }(F) \text { education }\end{array}$} & $1939-50$ & 29.48 & 19.02 \\
\hline & $1951-55$ & 10.58 & 10.80 \\
\hline & $1956-60$ & 11.69 & 12.45 \\
\hline & 1961-65 & 10.83 & 16.27 \\
\hline & 1966-70 & 13.21 & 15.60 \\
\hline & 1971-75 & 15.00 & 16.18 \\
\hline & 1976-78 & 9.22 & 9.68 \\
\hline
\end{tabular}


...table 8 continued

\begin{tabular}{llrr}
\hline \hline & Variable & Germany & France \\
& $(\%)$ & $(\%)$ \\
\hline End of secondary education & $1945-50$ & 13.58 & 11.92 \\
& $1951-55$ & 14.39 & 9.42 \\
& $1956-60$ & 10.65 & 9.33 \\
& $1961-65$ & 11.16 & 13.29 \\
& $1966-70$ & 10.48 & 14.32 \\
& $1971-75$ & 11.53 & 14.42 \\
& $1976-80$ & 15.48 & 14.64 \\
Mother's education & 1981-86 & 12.73 & 12.67 \\
& No vocational degree & 43.98 & 82.88 \\
& Basic voc. degree & 36.66 & 7.16 \\
& Intermediate qualif. & 3.39 & 4.29 \\
& Higher education & 1.16 & 3.54 \\
& Missing & 14.80 & 2.14 \\
& No vocational degree & 12.39 & 72.07 \\
& Basic voc. degree & 52.88 & 11.94 \\
& Intermediate qualif. & 12.63 & 5.14 \\
& Higher education & 6.90 & 6.74 \\
& Missing & 15.20 & 4.12 \\
& Worker & 35.62 & 33.23 \\
& Farmer & 5.57 & 12.96 \\
& Self-employed & 7.95 & 11.20 \\
& Senior manager & 10.41 & 7.26 \\
& Middle manager & 13.34 & 9.91 \\
& Employee & 4.07 & 9.00 \\
& Missing & 23.03 & 16.43 \\
\hline \hline
\end{tabular}

